\title{
Sphingosine 1-phosphate Receptor Modulator Therapy for Multiple Sclerosis: Differential Downstream Receptor Signalling and Clinical Profile Effects
}

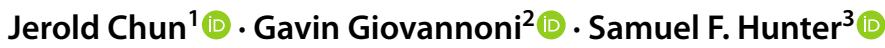

Published online: 8 December 2020

(c) The Author(s) 2020

\begin{abstract}
Lysophospholipids are a class of bioactive lipid molecules that produce their effects through various $\mathrm{G}$ protein-coupled receptors (GPCRs). Sphingosine 1-phosphate (S1P) is perhaps the most studied lysophospholipid and has a role in a wide range of physiological and pathophysiological events, via signalling through five distinct GPCR subtypes, $\mathrm{S}_{\mathrm{PR}} \mathrm{t}_{1} \mathrm{~S}_{\mathrm{PR}}$. Previous and continuing investigation of the S1P pathway has led to the approval of three S1PR modulators, fingolimod, siponimod and ozanimod, as medicines for patients with multiple sclerosis (MS), as well as the identification of new S1PR modulators currently in clinical development, including ponesimod and etrasimod. S1PR modulators have complex effects on S1PRs, in some cases acting both as traditional agonists as well as agonists that produce functional antagonism. S1PR subtype specificity influences their downstream effects, including aspects of their benefit:risk profile. Some S1PR modulators are prodrugs, which require metabolic modification such as phosphorylation via sphingosine kinases, resulting in different pharmacokinetics and bioavailability, contrasting with others that are direct modulators of the receptors. The complex interplay of these characteristics dictates the clinical profile of S1PR modulators. This review focuses on the S1P pathway, the characteristics and S1PR binding profiles of S1PR modulators, the mechanisms of action of S1PR modulators with regard to immune cell trafficking and neuroprotection in MS, together with a summary of the clinical effectiveness of the S1PR modulators that are approved or in late-stage development for patients with MS.
\end{abstract}

Jerold Chun, Gavin Giovannoni and Samuel F. Hunter have all contributed equally.

Enhanced Digital Features To view enhanced digital features for this article, go to https://doi.org/10.6084/m9.figshare.13133288.

Electronic supplementary material The online version of this article (https://doi.org/10.1007/s40265-020-01431-8) contains supplementary material, which is available to authorized users.

Gavin Giovannoni

g.giovannoni@qmul.ac.uk

Jerold Chun

jchun@sbpdiscovery.org

Samuel F. Hunter

sfhunter@neurosci.us

1 Sanford Burnham Prebys Medical Discovery Institute, 10901 North Torrey Pines Road, La Jolla, CA 92037, USA

2 Blizard Institute, Barts and The London School of Medicine and Dentistry, Queen Mary University of London, 4 Newark St, London E1 2AT, UK

3 Advanced Neurosciences Institute, 101 Forrest Crossing Blvd STE 103, Franklin, TN 37064, USA

\section{Introduction}

Lysophospholipids are a class of bioactive lipid molecules that produce their effects through a large number of $G$ protein-coupled receptors (GPCRs). The lysophospholipid receptor family is characterised according to its specific ligands, which include the lysophosphatidic acid (LPA), lysophosphatidyl inositol, lysophosphatidyl serine and sphingosine 1-phosphate (S1P) receptors (Fig. 1) [1-3]. S1P is perhaps the most studied lysophospholipid and has roles in a wide range of physiological and pathophysiological events. S1P acts as an extracellular signalling molecule and its numerous biological functions affect most organ systems including the immune system, the central nervous system (CNS), the blood-brain barrier (BBB) and the cardiovascular system. Its actions are mediated by five distinct GPCR subtypes $\left(\mathrm{S}_{1} \mathrm{PR}_{1}\right.$ to $\left.\mathrm{S} 1 \mathrm{PR}_{5}\right)$ that themselves have distinct signalling properties (Figs. 1, 2). S1P has been implicated in a range of diseases, including inflammation, cancer, atherosclerosis and diabetes, as well as multiple sclerosis (MS), where it is increased in the cerebrospinal fluid and brain 


\section{Key Points}

Previous and continuing investigation of S1P (a bioactive lysophospholipid) and the modulation of the S1P signalling pathway through five distinct GPCR subtypes $\left(\mathrm{S}_{1 \mathrm{PR}}\right.$ to $\left.\mathrm{S}_{1 \mathrm{PR}}\right)$ has led to the approval of three S1PR modulators, fingolimod, siponimod and ozanimod, as medicines for patients with MS, as well as the identification of new S1PR modulators currently in clinical development.

S1PR modulators have complex effects on S1PRs, acting both as agonists with functional antagonism $\left(\mathrm{S}_{1} \mathrm{PR}_{1}\right)$ and as presumed agonists $\left(\mathrm{S}_{\mathrm{PR}} \mathrm{PR}_{3,5}\right)$. For all S1PR modulators, the complex interplay of these modes of action, S1PR subtype specificity and variable requirement for in vivo phosphorylation or other metabolic steps for activity dictate their pharmacokinetics, bioavailability and ultimately their clinical profile.

In MS, the mechanisms of action of S1PR modulators have positive effects with regard to immune cell trafficking, and likely effects in the CNS which may lead to neuroprotection; second-generation modulators with good bioavailability, high specificity for and activity at $\mathrm{S}_{1 \mathrm{PR}_{1}}$ and $\mathrm{S}_{\mathrm{PR}} \mathrm{PR}_{5}$ may, together with dose titration, avoid some side effects associated with this drug class while maximising potential clinical benefit, including in progressive forms of MS.

parenchyma of patients. Previous and continuing investigation of the S1P pathway has led to approved medicines as well as the identification of potential new targets for further therapeutic intervention [4].

Fingolimod (FTY720; Gilenya ${ }^{\circledR}$ ) is approved for the treatment of patients with relapsing forms of MS (RMS), as well as for use in paediatric patients with MS; it was the first S1P receptor (S1PR) modulator approved for the treatment of any disease. Several second-generation S1PR modulators have been, or are currently being, developed for MS, including amiselimod, ceralifimod, etrasimod, GSK2018682, ozanimod, ponesimod and siponimod. Among these agents, siponimod (BAF312; Mayzent ${ }^{\circledR}$ ) was recently approved for use in adults with RMS, including active secondary progressive MS (SPMS) in the USA, active SPMS in Europe, and SPMS in Australia and Japan [5-8]. It is the only oral agent to complete a successful Phase 3 clinical study in patients with SPMS [9]. Ozanimod $\left(\right.$ Zeposia $\left.^{\circledR}\right)$ has also been approved in the USA for use in adults with RMS, including active SPMS [10], although clinical trials were limited to patients with RMS [11, 12]. Ozanimod has also been approved in Europe in patients with relapsing-remitting multiple sclerosis (RRMS) [13]. S1P modulators have complex actions on receptors, in some cases acting both as agonists with functional antagonism, and as traditional agonists. Furthermore, some of the modulators are prodrugs that require phosphorylation or other metabolic steps, resulting in different pharmacokinetics, whereas others are direct modulators of the receptor.

This review focuses on the S1P pathway, the characteristics and S1PR binding profiles of S1PR modulators, the mechanisms of action of S1PR modulators with regard to immune cell trafficking and neuroprotective activities in MS, together with a summary of the clinical effectiveness of S1PR modulators in patients with MS.

\section{S1P and S1PR Modulators}

\subsection{S1P Structure, Function and Distribution}

S1P is a lysophospholipid with a polar head-group and lipophilic tail, produced intracellularly via phosphorylation of sphingosine that is synthesised through the metabolic recycling of sphingolipids or de novo sphingolipid biosynthesis $[14,15]$. S1P is a potent signalling molecule that is biologically known to be an extracellular lipid mediator acting through defined receptors [15-18], with roles in many processes including angiogenesis, cell growth, survival, motility, cytoskeletal rearrangement, neural development, CNS cell functions and immune cell trafficking [19-22]. Indeed, knockout mice with impaired S1P synthesis or S1PR expression often have vascular or neurogenic defects, and lead to embryonic lethality in the case of $\mathrm{S}_{\mathrm{PR}}$ knockouts and sphingosine kinase 1/2 double knockouts [23,24]. Multiple cell types can release S1P into plasma, but erythrocytes are probably the main contributor of plasma S1P [25].

$\mathrm{S} 1 \mathrm{P}$ and sphingosine, as well as the parent lipid molecules ceramide and sphingomyelin, are in equilibrium depending on local tissue concentrations and the presence of key metabolic enzymes. Tissues vary widely in the presence of sphingomyelinase, ceramidase and sphingosine kinase 1 and 2, the enzymes relevant to the production of S1P. The presence of degradative S1P lyase, which hydrolyses S1P to phosphatidyl ethanolamine and hexadecanal, also determines local S1P concentrations and clearance [26]. Therapeutic S1PR ligands, such as those that closely resemble the structure of sphingosine 1-phosphate (i.e. fingolimod-phosphate), are also affected by one or more of these enzymes.

Approximately $70 \%$ of plasma S1P is carried by apolipoprotein $\mathrm{M}(\mathrm{apoM})$ as part of the high density lipoprotein (HDL) [27], and the remaining $30 \%$ by albumin [25]. Endothelial cells comprising part of the BBB secrete apoM, into both the bloodstream and the brain. It has been hypothesised that HDL-apoM particles containing S1P are taken 


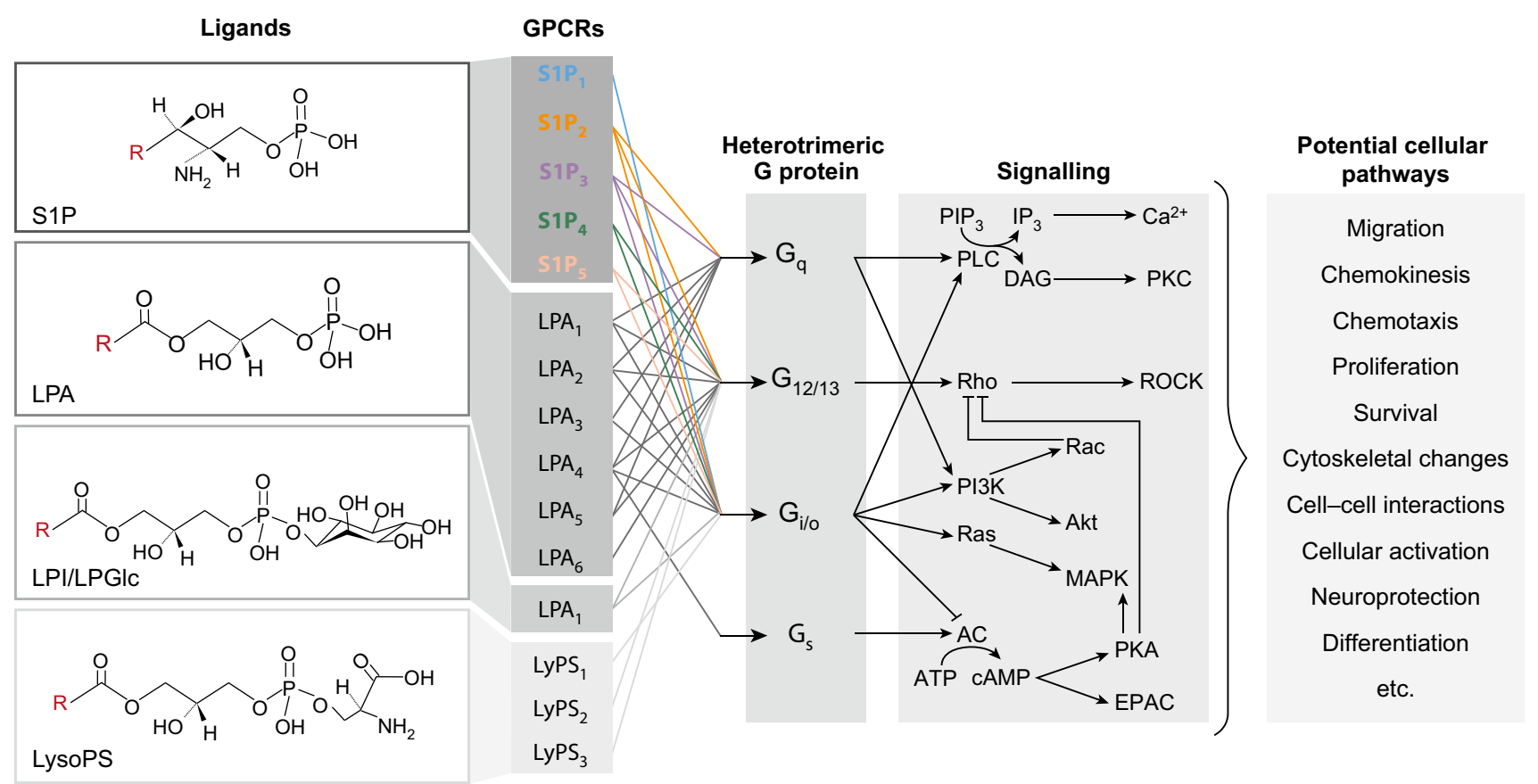

Fig. 1 Lysophospholipid receptors and their downstream intracellular signalling pathways. Lysophospholipid ligands (S1P, LPA, LPI and LysoPS) bind to their cognate GPCRs, which activate heterotrimeric G-proteins (defined here by their $\alpha$ subunits) to initiate downstream signalling cascades. The five S1PRs are highlighted in coloured text. Major signalling pathways activated through $\mathrm{G}_{\mathrm{i} / \mathrm{o}}, \mathrm{G}_{\mathrm{q}}$, $G_{12 / 13}$ and $G_{s}$ proteins are shown. Signalling through $G_{i / o}$ can promote: (1) activation of the small GTPase Ras and the ERK to promote proliferation; (2) activation of $\mathrm{PI} 3 \mathrm{~K}$ and $\mathrm{PKB} / \mathrm{Akt}$ to increase survival and to prevent apoptosis with important implications for neuroprotection; (3) induction of PI3K and the small GTPase Rac to promote migration, to enhance endothelial barrier function and to induce vasodilation; and (4) activation of PKC and PLC to increase intracellular free calcium $\left(\mathrm{Ca}^{2+}\right)$, which is required for many cellular responses. Furthermore, signalling through $\mathrm{G}_{\mathrm{i} / \mathrm{o}}$ can inhibit $\mathrm{AC}$ activity to reduce cAMP. Signalling through $\mathrm{G}_{\mathrm{q}}$ primarily activates PLC

up by cells of the BBB and transported into the brain parenchyma, leading to increased intracerebral S1P [28].

\subsection{S1PR Subtypes and Modulators}

S1P shows binding affinity for five different S1PR subtypes $\left(\mathrm{S} 1 \mathrm{PR}_{1}\right.$ to $\left.\mathrm{S} 1 \mathrm{PR}_{5}\right)$, through which cellular signals are transduced [29]. Based on the structural characterisation of $\mathrm{S}_{1 R_{1}}, \mathrm{~S} 1 \mathrm{P}$ translocates through the membrane bi-layer into the linear-appearing active site, with the anionic phosphate group on S1P interacting with the cationic side-chains of arginine residues within $\mathrm{S}_{\mathrm{PR}}$, and a protonated amino group adjacent to the phosphate group in S1P interacting with the anionic side-chain of a neighbouring glutamate residue in the S1PR 1 polypeptide [30-32]. Mechanistic steps may vary for S1P presented to its cognate receptor when bound to a chaperone protein [33]. pathways and signalling through $\mathrm{G}_{12 / 13}$ can promote activation of the small GTPase Rho and the ROCK to inhibit migration, to reduce endothelial barrier function and to induce vasoconstriction. S1PR signalling does not appear to be transduced via $\mathrm{G}_{\mathrm{s}}$. Figure elements reproduced/adapted with permission $[15,55] . A C$ adenylyl cyclase, $A T P$ adenosine triphosphate, $c A M P$ cyclic adenosine monophosphate, $D A G$ diacylglycerol, $E P A C$ exchange protein activated by cAMP, ERK extracellular signal-regulated kinase, GPCRs G-protein coupled receptors, GTPase guanosine triphosphatase, $I P_{3}$ inositol triphosphate, LPA lysophosphatidic acid, LPI lysophosphatidyl inositol, LysoPS lysophosphatidyl serine, MAPK mitogen-activated protein kinase, PI3K phosphatidylinositol 3-kinase, PIP phopsatydlinositol phosphate, $P K A$ protein kinase A, $P L C$ phospholipase C, $P K B$ / $A k t$ protein kinase $\mathrm{B}, P K C$ protein kinase $\mathrm{C}, R O C K$ Rho-associated kinase, S1P sphingosine 1-phosphate, S1PRs sphingosine 1-phosphate receptors

Most S1PR modulators in clinical development or approved for MS treatment display high affinity for $\mathrm{S}_{\mathrm{PR}}$, and typically one or more of the other S1PR subtypes; efforts to synthesise functional analogues have generated molecules with a range of affinities for other S1PR subtypes (Table 1 and Online Resource Table 1) [29]. Some S1PR modulators, including fingolimod, are prodrugs, which must be phosphorylated by sphingosine kinases before they display high binding affinity for S1PRs [34, 35]. Several second-generation S1PR modulators, such as siponimod, have been designed to include moieties that mimic the terminal phosphate group of S1P and therefore do not require phosphorylation for activity [36]. Terminal phosphorylation is also thought to contribute to the relatively long elimination half-life $\left(t_{1 / 2}\right)$ of fingolimod and other prodrugs [35, 37], compared with other S1PR modulators. 


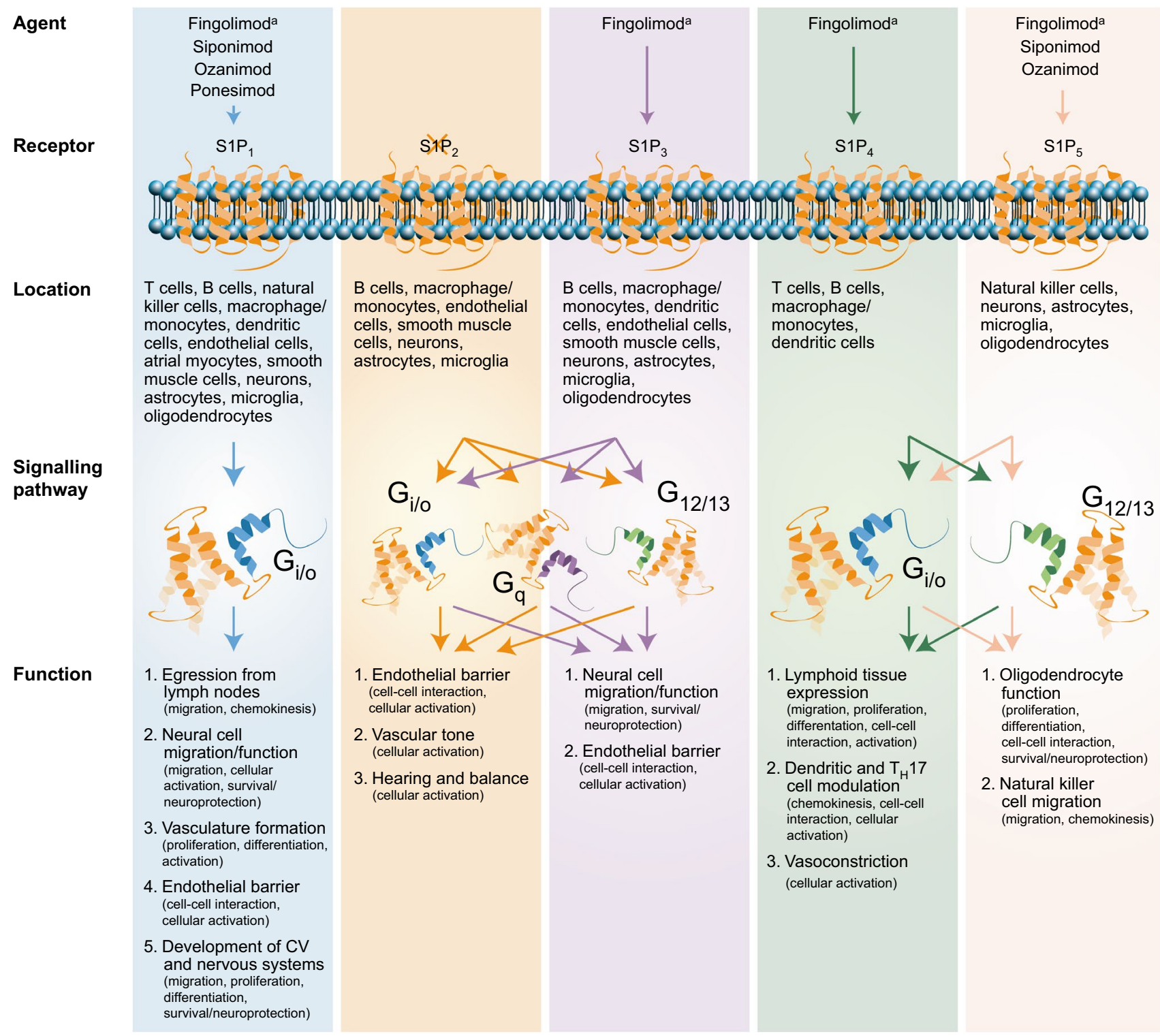

Fig. 2 Interaction of S1PR modulators with S1PR subtypes, downstream $G \alpha$ subunit targets and their physiological consequences. S1PR modulators are agonists of $\mathrm{S}_{\mathrm{PR}}$ and produce functional antagonism. Therefore, the net effect of treatment would be to depress signalling through these pathways. In contrast, S1PR modulators appear to act as traditional agonists of $\mathrm{S}_{\mathrm{PR}}$; the expected outcome of treatment would therefore be increased activity through these pathways, although forms of antagonism may occur. Crosstalk between S1PRs and downstream G-protein signalling occurs, with some (but

Other structural refinements in second-generation S1PR modulators have focused on trying to minimise binding to $\mathrm{S}_{1 \mathrm{PR}}$, which was believed to mediate chronotropic cardiac effects, and also to improve penetration into the brain [30]. The characterisation of S1PR -mediated effects in mice has shown that the distribution and function of this receptor subtype in the ventricular cardiac conduction system are suggestive of a direct mechanism for the risk not all) crosstalk depicted (coloured arrows); potential crosstalk through $G_{q}$ and resulting downstream calcium signalling may have neuroprotective effects. It is important to note that the different pathways are subject to regulation by other activation and differentiation signals that may also affect the relative expression of individual S1PR subtypes on individual cells. Figure elements reproduced/adapted with permission $[15,55]$. ${ }^{2}$ Requires phosphorylation in situ for activity. $C V$ cardiovascular, S1P sphingosine 1-phosphate, S1PR sphingosine 1-phosphate receptor, $T_{H} 17$ T-helper cell

of type I and type II atrioventricular block [38]. However, this is a species-specific difference that appears not to occur in humans. Siponimod and other S1PR modulators that have very low affinity for $\mathrm{S}_{1} \mathrm{PR}_{3}$ are associated with some first-dose cardiac effects [39, 40], suggesting that chronotropy in humans is also governed by $\mathrm{S}_{\mathrm{PR}}$, which had resulted in first-dose observation (FDO) for fingolimod to address heart rate reductions produced by initial 
Table 1 Sphingosine 1-phosphate receptor (S1PR) modulator structures, receptor subtype interactions (adapted from Vogt and Stark [29]) and summary of S1PR modulator pharmacokinetics and pharmacodynamics. Reproduced with permission from Comi [55]

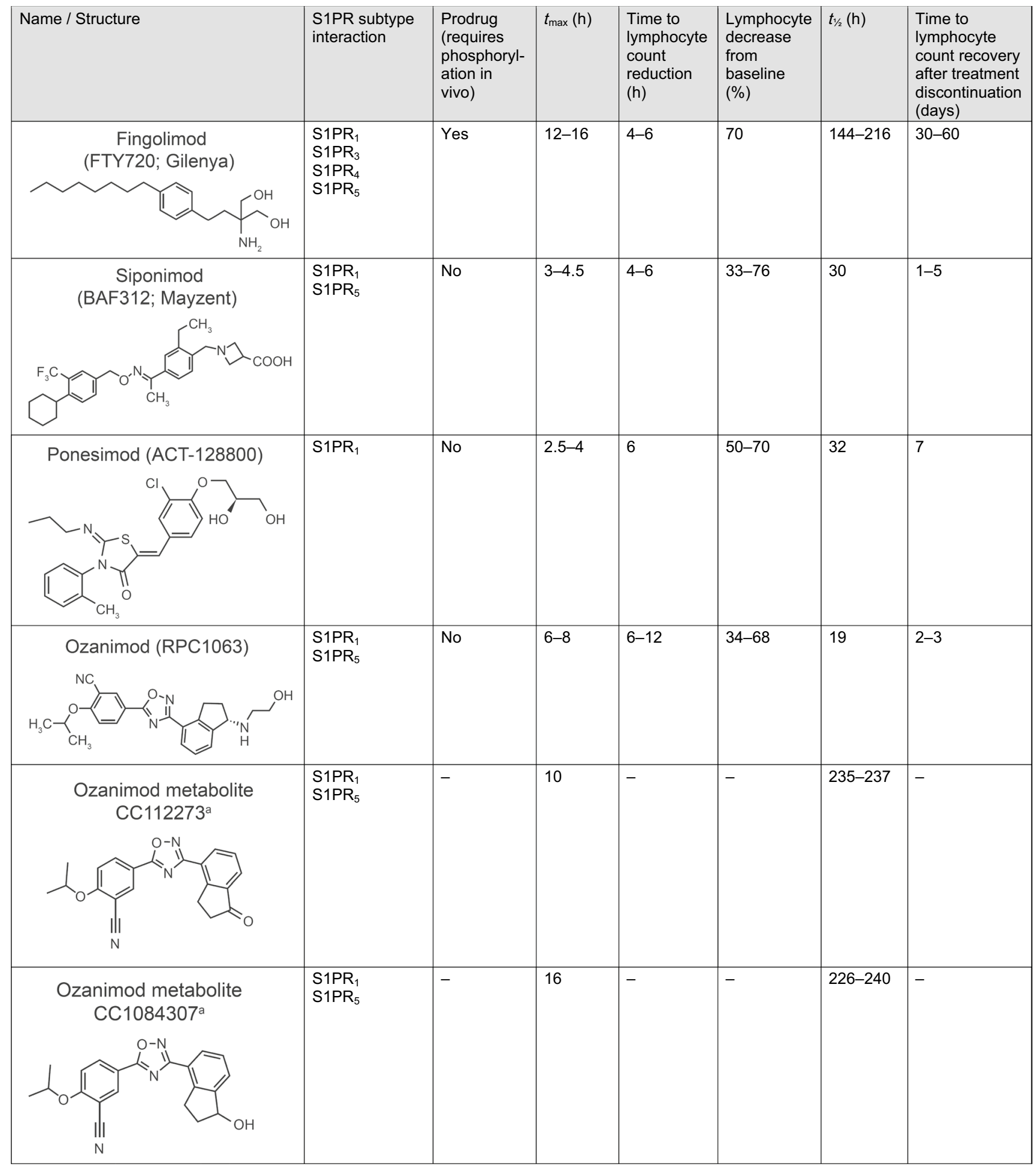

${ }^{\text {a }}$ Data from Tran et al. [64]

$t_{\max }$ time to maximum plasma concentration, $t_{1 / 2}$ elimination half-life

receptor agonism (see Sect. 4.2 for details). However, the pharmacodynamic reduction in heart rate can be circumvented by implementation of drug titration for the first
4-5 days of treatment, as demonstrated in most patients being treated with siponimod [5] and in the ozanimod trials $[11,12]$. 
Fingolimod has also been shown to induce the inflammatory mediator cyclooxygenase 2 (COX2) in rat astrocyte cell cultures [41], and increase COX2 expression in mice and human HepG2 cell cultures via S1PR 3 [42, 43], suggesting that activity at this receptor may contribute to inflammatory processes. However, unlike S1P, in vitro studies have shown that fingolimod may be a partial agonist of $\mathrm{S}_{\mathrm{PR}} \mathrm{PR}_{3}$ compared with S1P, and possibly have antagonistic properties under certain conditions [44-46], so the biological significance of this observation is unclear.

All S1PR modulators targeting S1PR 1 appear to produce functional antagonism with chronic drug exposure, thus producing a paradoxical loss of receptor signalling as part of the mechanism of action, with no evidence of compensatory receptor upregulation.

\section{S1PRs: Molecular Structure and Signal Transduction}

\subsection{Phylogeny of S1PR Subtypes}

Various S1PR genes were identified by deoxyribonucleic acid (DNA) sequence homology to orphan receptor genes following functional characterisation of the first identified member of the lysophospholipid receptor family, LPA (Fig. 3) [15]. The five $\mathrm{S} 1 \mathrm{PR}$ subtypes $\left(\mathrm{S} 1 \mathrm{PR}_{1}\right.$ to $\left.\mathrm{S} 1 \mathrm{PR}_{5}\right)$ are conserved across phylogeny at the polypeptide sequence level [47].

Each receptor-subtype clusters among its particular subtype in other species, rather than among other subtypes of its own species, with $\mathrm{S} 1 \mathrm{PR}_{1}, \mathrm{~S}_{1} \mathrm{PR}_{3}$ and $\mathrm{S} 1 \mathrm{PR}_{5}$ more closely related to each other than they are to $S 1 \mathrm{PR}_{2}$ and $\mathrm{S} 1 \mathrm{PR}_{4}$. $\mathrm{S}_{1 \mathrm{PR}_{4}}$ exhibits the most divergence from the other subtypes [47]. This relatedness across species suggests that results from animal models may well reflect similar function in humans, but there are exceptions; for example, the species-

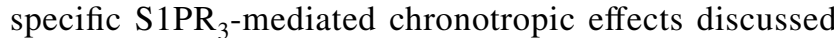
above. Divergence of the different subtypes was likely an evolutionary event, and the level of sequence conservation after divergence suggests differentiated functional roles for each subtype across species. The next most related family of receptor genes compared to lysophospholipid receptors are the cannabinoid receptors CB1 and CB2. Structural analyses have revealed shared and distinct features for $S 1 \mathrm{PR}_{1}$ and $\mathrm{LPA}_{1}$, the latter with a binding pocket capable of accommodating both LPAs and phosphorylated endocannabinoids, underscoring further relationships amongst these lipid GPCRs [32, 33].

\subsection{Distributions}

The distributions of $\mathrm{S}_{1} \mathrm{PR}_{1-5}$ with their key biological roles are summarised in Fig. 2 and are described here in brief.

The $\mathrm{S}_{1 \mathrm{PR}}$ subtype is expressed on lymphocytes where it mediates lymphocyte migration from lymph nodes [48]. This subtype is also found on cells of the nervous system, including neural progenitor cells, astrocytes and oligodendrocytes, where it acts to influence neurogenesis, cell migration, neurotransmission and survival [49]. Its expression on endothelial cells affects vasculature formation and endothelial barrier function, which, combined with expression on astrocytes, regulates BBB function [50]. In addition, expression on atrial myocytes mediates cardiovascular effects [39].

$\mathrm{S}_{1 \mathrm{PR}_{2}}$ is expressed on cells of the CNS (neurons, astrocytes and microglia), endothelial cells and smooth muscle cells, and has been implicated in endothelial barrier function and vascular tone, hearing and vestibular function [50, 51]. $\mathrm{S}_{1} \mathrm{PR}_{3}$ expression is similar to that of $\mathrm{S} 1 \mathrm{PR}_{2}$ but includes oligodendrocytes in the CNS; it influences endothelial barrier function, neural cell migration and astrocyte activities $[49,51] . \mathrm{S}_{1} \mathrm{PR}_{4}$ is mainly expressed on lymphocytic
Fig. 3 Phylogenetic relationships between S1PRs and other LP receptor family members. Phylogenetic tree of human $\mathrm{G}$-protein coupled receptors and LP receptors. GPCR G-protein coupled receptor, $L P$ lysophospholipid, LPA lysophosphatidic acid receptor, $L P I$ lysophosphatidyl inositol receptor, $L y P S$ lysophosphatidyl serine receptor, $S 1 P$ sphingosine 1 -phosphate receptor. Reproduced/adapted with permission from Chun [15]

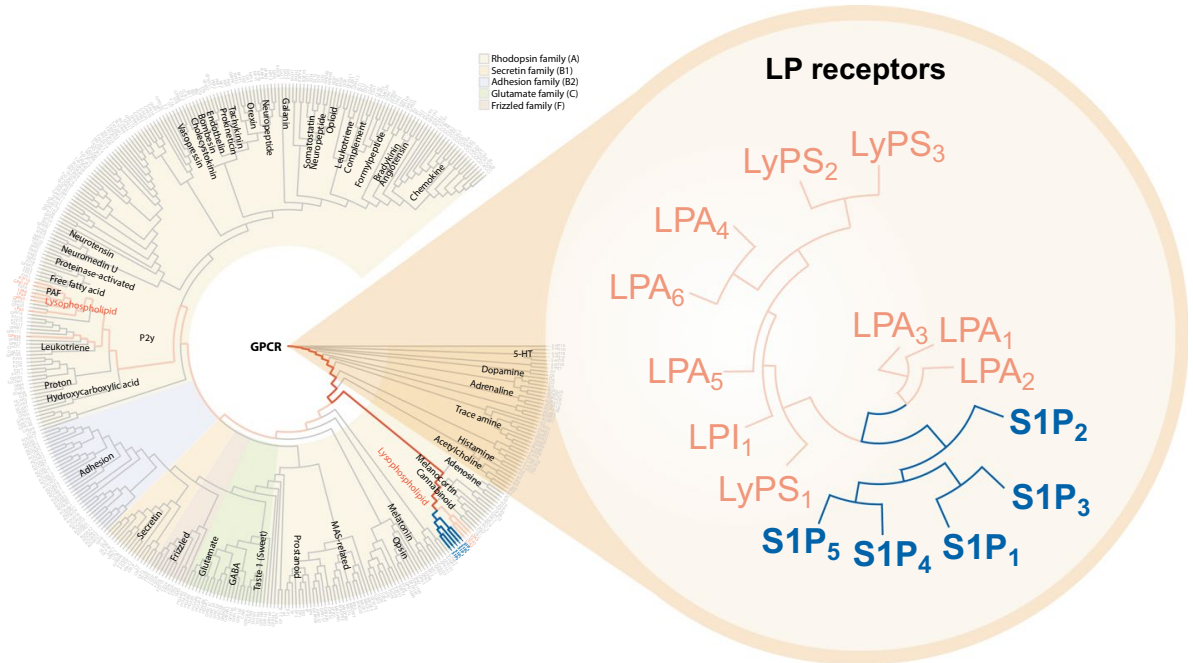


and haematopoietic cells but it has also been detected on human airway smooth muscle cells [2, 52]. It is involved in lymphocyte migration as well as dendritic and T-helper 17 (Th17)-cell modulation [53, 54]. Its expression on airway smooth muscle cells appears to be associated with bronchospastic effects. $\mathrm{S}_{1} \mathrm{PR}_{5}$ is mainly expressed on oligodendrocytes in the CNS, and on natural killer cells and other lymphocytes in the spleen, mediating cell functions and cell migration $[55,56]$.

\subsection{Signalling Pathways}

The tissue distribution and pathways that transduce S1PRligand-binding signals are instrumental in eliciting the effects observed at a physiological level. Characterisation of the respective $G$ protein-coupled signalling pathways associated with different S1PR subtypes has revealed evidence of both redundancy and differentiation among them (Figs. 1, 2) $[52,54]$.

Signal transduction through GPCRs occurs via G proteins, which are heterotrimeric protein complexes comprising a $\mathrm{G}_{\alpha}$ subunit and a dimeric $\mathrm{G}_{\beta} \mathrm{G}_{\gamma}$ subunit. When a ligand binds to a GPCR, the $\mathrm{G}_{\alpha}$ subunit undergoes a conformational change and dissociates from the $\mathrm{G}_{\beta} \mathrm{G}_{\gamma}$ dimer. The dissociated subunits then interact with other signal transduction proteins to propagate the ligand-binding signal.

There are four subclasses of $G_{\alpha}$ subunit $\left(G_{s}, G_{i / o}, G_{q}\right.$, $\mathrm{G}_{12 / 13}$; Fig. 1) and S1PRs act through various combinations of three of these subunits. $\mathrm{S}_{\mathrm{PR}}$ primarily couples through $\mathrm{G}_{\mathrm{i} / \mathrm{o}}$, while $\mathrm{S} 1 \mathrm{PR}_{2}$ and $\mathrm{S} 1 \mathrm{PR}_{3}$ couple through $\mathrm{G}_{\mathrm{i} / \mathrm{o}}, \mathrm{G}_{\mathrm{q}}$ and $\mathrm{G}_{12 / 13}$, and $\mathrm{S} 1 \mathrm{PR}_{4}$ and $\mathrm{S} 1 \mathrm{PR}_{5}$ couple through $\mathrm{G}_{\mathrm{i} / \mathrm{o}}$ and $\mathrm{G}_{12 / 13}$ (Fig. 2) $[1,57,58]$. These interactions lead to activation of several classical pathways downstream of these G proteins, including adenylyl cyclase inhibition, the Ras/MAP kinase cascade, phosphatidylinositol 3-phosphate kinase/Akt for $G_{i / o}$, phospholipase $C$ for $G_{q}$, and small Rho GTPases for $\mathrm{G}_{12 / 13}$. Different downstream signalling events promote effects such as cell-cell communication in the CNS and cell proliferation, survival and migration [54, 58] (Fig. 1). Crosstalk between different GPCR-mediated pathways extends to other members of the lysophospholipid family, with additional $G_{\alpha}$ subunits $\left(G_{s}, G_{11}\right)$ involved in LPA signal transduction $[1,15]$.

\section{Pharmacodynamic and Pharmacokinetic Profiles of the S1PR Modulators}

\subsection{Characteristics and S1PR Binding Profiles of S1PR Modulators}

Fingolimod was the first S1PR modulator (and the first oral agent) approved for the treatment of patients with MS [55], and there are currently a number of other S1PR modulators at various stages of clinical development or recently approved for the treatment of MS. Siponimod, a secondgeneration S1PR modulator, was recently approved for use in adults with RMS, including clinically isolated syndrome, RRMS, and active SPMS in the USA, active SPMS in Europe and SPMS in Australia and Japan [5-8, 59]. Ozanimod (RPC1063) is approved for use in adults with RMS, including clinically isolated syndrome, RRMS and active SPMS in the USA [10], and in Europe in patients with RRMS [13], and ponesimod (ACT-128800) is being evaluated in RMS (Table 1). Ozanimod and etrasimod are also being evaluated for use in inflammatory bowel disease, and ponesimod in psoriasis. Other S1PR modulators include ceralifimod (ONO-4641) and amiselimod (MT-1303), which were assessed in patients with RMS but are no longer in clinical development for MS; GSK2018682, which was evaluated in healthy volunteers but not developed further in MS; and etrasimod (APD334), which is currently being evaluated for the treatment of ulcerative colitis and atopic dermatitis (Online Resource Table 1). S1PR modulators approved or currently in development for MS are discussed further in the sections to follow.

These S1PR modulators differ in their affinities for S1PR subtypes (Fig. 2). Fingolimod (when phosphorylated) targets four of the receptor subtypes $\left(\mathrm{S}_{\mathrm{PR}}, \mathrm{S}_{1} \mathrm{PR}_{3}, \mathrm{~S}_{\mathrm{PPR}}\right.$ and $\mathrm{S}_{\mathrm{P}} \mathrm{PR}_{5}$ ), while siponimod and ozanimod target $\mathrm{S}_{1} \mathrm{PR}_{1}$ and $\mathrm{S}_{1} \mathrm{PR}_{5}[55,60]$, and ponesimod [61, 62] shows high affinity for $\mathrm{S}_{1} \mathrm{PR}_{1}$. Notably, fingolimod is a prodrug and must be phosphorylated by sphingosine kinase before it displays binding affinity for S1PRs [34].

Fingolimod-phosphate has affinities (or effective concentration to half-maximal response; $\mathrm{EC}_{50}$ ) in the sub-nanomolar to nanomolar range for four receptor subtypes $\left(\mathrm{S}_{\mathrm{PRR}}\right.$, $\mathrm{S}_{1 \mathrm{PR}_{3}}, \mathrm{~S}_{1 \mathrm{PR}_{4}}$ and $\mathrm{S} 1 \mathrm{PR}_{5}$ ) [30, 54], although some studies suggest that fingolimod-phosphate shows weaker binding to $\mathrm{S}_{1 \mathrm{PR}_{4}}$ than to the other three subtypes [35, 60]. Siponimod is selective for $\mathrm{S}_{\mathrm{PR}}$ and $\mathrm{S} 1 \mathrm{PR}_{5}$, with affinities in the subnanomolar range for both receptor subtypes, and shows only low affinity for $\mathrm{S}_{1} \mathrm{PR}_{3}(>1000 \mathrm{nM})$ and $\mathrm{S}_{\mathrm{PR}}(750 \mathrm{nM})$ [39]. Both fingolimod and siponimod lack affinity for $\mathrm{S}_{1} \mathrm{PR}_{2}$ $\left(\mathrm{EC}_{50}>10,000 \mathrm{nM}\right)[39,54]$.

Ozanimod is also specific for $\mathrm{S}_{1} \mathrm{PR}_{1}$ and $\mathrm{S}_{1} \mathrm{PR}_{5}$ [60]; it has an affinity for $\mathrm{S}_{1} \mathrm{PR}_{1}$ similar to that of siponimod but an affinity for $\mathrm{S}_{1 \mathrm{PR}}$ that is approximately 10 -fold weaker [60]. The pharmacology and metabolism of ozanimod, while described, remain complex. The complexity was not recognised early in development, leading to additional, significant ongoing investigation into the metabolites of ozanimod. Studies in healthy volunteers showed that ozanimod is cleared faster than siponimod, with an elimination $t_{1 / 2}$ of 17-21 h [63], compared with approximately $30 \mathrm{~h}$ for siponimod [39], although head-to-head comparisons have 
not been done. However, following multiple dose administration of ozanimod in healthy people, two major metabolites of ozanimod represent most of the circulating total active drug exposure (CC112273 and CC1084307; 73\% and $15 \%$, respectively); ozanimod represents $6 \%$, with other active minor metabolites making up the remainder, including RP101075 [64]. Ozanimod metabolism steps appear to begin with irreversible $N$-dealkylation to RP101075, either directly by cytochrome P450 (CYP) 3A4 and 1A1, or via an intermediate (RP101988; driven by alcohol- or aldehydedehydrogenases). RP101075 is then either terminally converted to another minor active metabolite (RP112289) by CYP3A4/5 $N$-hydroxylation or converted via monoamine oxidase $\mathrm{B}$ (MAO-B) to form the most abundant major active metabolite $\mathrm{CC} 112273$, which exists in reversible equilibrium with the less abundant but more potent major active metabolite, CC1084307 [64].

Preclinical studies have shown that the pharmacokinetic properties of the first two minor active metabolites (RP101988 and RP101075) are similar to those of ozanimod; the minor metabolites also have similar affinities to ozanimod for S1PR 1 and $\mathrm{S}_{1 \mathrm{PR}_{5}}$ [65]. The downstream active metabolites in humans, including the major metabolites CC112273 and CC1084307, have only recently been characterised and available data regarding their properties are limited. Most have a distinct pharmacokinetic profile compared with ozanimod, with a $t_{1 / 2}$ of 10-13 days [66]. CC112273 is several-fold less potent than ozanimod for $\mathrm{S}_{1 \mathrm{PR}_{1}}$ and $\mathrm{S} 1 \mathrm{PR}_{5}$, and is thought to account for the majority of ozanimod activity in humans owing to its relative abundance [64]. Importantly, the less abundant major active metabolite $\mathrm{CC} 1084307$ is about ten times as potent as the more abundant major active metabolite $\mathrm{CC} 112273$, and fivefold as potent as the parent ozanimod molecule, although it is present at one tenth the concentration of (and in reversible equilibrium with) CC112273 [64]. Therefore, in the average human, the two metabolites likely contribute similarly to $\mathrm{S} 1 \mathrm{P}$ receptor effects, together with a minor contribution of the parent drug. In contrast, ponesimod is specific for $\mathrm{S}_{\mathrm{PR}} \mathrm{R}_{1}$, with little or no affinity for the other receptor subtypes, relatively little biotransformation and no active metabolites [61, $67,68]$; it has an elimination $t_{1 / 2}$ of approximately $22-67 \mathrm{~h}$ $[61,68]$.

The initially proposed main mechanism of action of fingolimod and siponimod in MS is slowing of the egress of lymphocytes from lymph nodes, an effect mediated by functional antagonism at $\mathrm{S}_{1 P R_{1}}[52,54,69]$. This reduces the number of circulating central memory $\mathrm{T}$ cells, including potentially autoreactive $\mathrm{T}$ cells, which can stimulate MS-related inflammation if they reach the CNS $[69,70]$. In addition, it is likely that a second, distinct CNS mechanism targeting S1PRs in astrocytes and other resident CNS cells operates in parallel to promote direct CNS effects, which also involves functional antagonism receptor mechanisms. These conclusions are supported by multiple lines of evidence, including animal studies employing astrocyte-specific receptor deletion [71], paradoxical dose responses in clinical trials where efficacy does not track with increasing dose [72-74], and brain volume preservation of fingolimod [72-74] and siponimod [9], which contrast with pseudoatrophy produced by anti-inflammatory therapies such as natalizumab [75]. These mechanisms are discussed in more detail in the following sections.

\subsection{Functional Antagonism and Agonism of S1PRs}

Functional antagonism occurs because ligand binding at $S 1 P R_{1}$ leads to the irreversible internalisation of $S 1 \mathrm{PR}_{1}$ and a loss of receptor signalling. Evidence suggests that when phosphorylated fingolimod binds to $\mathrm{S}_{1} \mathrm{PR}_{1}$ it first acts as a potent agonist, accounting for transient cardiac side effects [76], but this is rapidly superseded by functional antagonism, whereby ligand binding causes $\mathrm{S}_{\mathrm{PR}}$ to be internalised and degraded [39, 69, 77]. Cell culture studies have shown that fingolimod and siponimod induce the internalisation of $\mathrm{S}_{\mathrm{PR}}$ in mouse astrocytes [77], and siponimod produces prominent internalisation of $\mathrm{S}_{\mathrm{PR}}$ in Chinese hamster ovary $(\mathrm{CHO})$ cells over-expressing human $\mathrm{S}_{1} \mathrm{PR}_{1}$ molecules [39]. All S1PR modulators targeting S1PR appear to produce functional antagonism with chronic drug exposure, resulting in a paradoxical loss of receptor signalling as part of the mechanism of action.

Siponimod and ozanimod have high affinity for S1PR and $\mathrm{S}_{1 \mathrm{PR}_{5}}$ and produce manageable chronotropic cardiac effects at initiation, via titration that bypasses a need for FDO, followed by expected reductions in peripheral blood lymphocyte count $[63,78]$. This profile is consistent with transient agonism and subsequent functional antagonism of $\mathrm{S} 1 \mathrm{PR}_{1}$. Ponesimod is specific for $\mathrm{S} 1 \mathrm{PR}_{1}$ and is not a prodrug. A reduction in lymphocyte count has also been observed with ponesimod [79]. Unlike fingolimod (requires phosphorylation) and ozanimod (metabolites make up the majority of activity), siponimod and ponesimod do not require further metabolism to produce the active molecule.

Although the internalisation of $\mathrm{S}_{1} \mathrm{PR}_{1}$ in response to ligand binding that leads to functional antagonism is well established, evidence suggests that the binding to $\mathrm{S}_{\mathrm{PR}}$ may not lead to receptor down-modulation or halt signalling in the same manner. A study of $\mathrm{CHO}$ cells expressing human $\mathrm{S}_{1} \mathrm{PR}_{1}, \mathrm{~S}_{\mathrm{PR}}$ or $\mathrm{S} 1 \mathrm{PR}_{5}$ showed dose-dependent receptor internalisation for $\mathrm{S}_{1 \mathrm{PR}_{1}}$ with fingolimod, siponimod and ozanimod, and complete internalisation of $\mathrm{S}_{\mathrm{PR}}$ with fingolimod, but not siponimod or ozanimod, in line with their receptor-binding profiles [80]. By contrast, none of the three compounds led to $\mathrm{S}_{\mathrm{PR}} \mathrm{PR}_{5}$ internalisation [80]. This suggests that fingolimod, siponimod and ozanimod 
may act as agonists at $\mathrm{S}_{\mathrm{PR}}$, in contrast to their activity at $\mathrm{S}_{1 \mathrm{PR}_{1}}$, although inhibition by non-internalisation mechanisms remains a possibility.

\subsection{Impact of Phosphorylation Requirements on Bioavailability of S1PR Modulators}

The penetration of a drug or prodrug into the CNS is affected by its lipophilicity, half-life, transport mechanisms and CNS metabolism (phosphorylation, oxidation), all of which can affect S1PR activity in the CNS [81]. Drugs may have different actions as the concentrations rise in the CNS compartment. Since steady state in the CNS is a function of half-life and partition, short half-life drugs are likely to reach this state rapidly. Sphingosine kinases and hydrolases differ in their distribution and activity, and the balance between them and the consequent effects on activity, are incompletely understood. In general, there is less phosphorylation in the CNS than in the periphery, hence phosphorylation of fingolimod in the CNS may be rate limiting in some of its effects, unlike in the periphery.

These considerations affect the metabolism and accessibility of S1P and fingolimod-phosphate, which likely do not penetrate as rapidly and directly into the CNS owing to their polarity. Indeed, while radiolabelled analogues of both fingolimod and siponimod readily cross the BBB [82, 83], imaging studies showed that the highest drug concentrations in the brain were observed 2 days after injection of fingolimod in human volunteers [83], and $24 \mathrm{~h}$ after injection of siponimod in non-human primates [82].

Preliminary studies in experimental autoimmune encephalomyelitis (EAE) mice showed differences in the bioavailability of fingolimod and siponimod in the brain. Brain penetration was 3- to 4-fold greater with fingolimod than with siponimod; at doses producing full lymphocyte depletion, the brain:blood ratio was 30-40:1 with fingolimod compared with 10:1 for siponimod [84]. However, the relevance of this finding is not yet clear, because drug levels in brain tissue do not indicate the levels of free drug available to act on receptors. A second study evaluating brain uptake showed that the brain:blood ratio for siponimod was similar in healthy mice and in EAE mice (5-6:1), indicating consistent exposure in inflamed and non-diseased brains [85]. When fed fingolimod-loaded diets, fingolimod and fingolimod-phosphate also had a similar brain:blood ratio in healthy mice (7-8:1 and 5-6:1, respectively); however, ratios for both were markedly higher in EAE animals, especially for fingolimod-phosphate (16-40:1) [85]. This suggests that, unlike siponimod, CNS penetration and distribution of fingolimod is dependent on the changes associated with EAE (and MS) pathology. Although the significance of this finding is also unclear, this may mean that the bioavailability of siponimod could be less affected by disease progression, including changes in metabolic and inflammatory processes.

In terms of the physiological profiles of these different S1PR modulators, the effects associated with transient agonism and subsequent functional antagonism of $\mathrm{S}_{\mathrm{PR}} \mathrm{PR}_{1}$ seen with fingolimod and siponimod would be expected to occur with any of the other modulators, as they all bind to $\mathrm{S}_{\mathrm{PPR}}$. In the CNS, functional antagonism of astrocytic S1PR reduces astrogliosis [71, 86, 87] and agonism of oligodendrocytic $\mathrm{S}_{\mathrm{PR}}$ is involved in cell survival and possibly in promoting myelination [88]. Human brain penetration of ozanimod (especially its biologically relevant metabolites) and ponesimod, along with their functional endpoints within the brain, are currently less clear.

\section{S1PR Modulation and Immune Cell Trafficking and Migration in MS}

\subsection{S1PR Modulation and Effects on Lymphocytes}

The effects of S1PR modulators on the trafficking of immune cells in MS is proposed as the primary mechanism of action for this drug class. Reduction in circulating levels of $\mathrm{T}$ lymphocytes begins with functional antagonism of $\mathrm{S}_{\mathrm{PR}}$ by any of the S1PR modulators discussed here. Binding to $\mathrm{S}_{\mathrm{PR}}$ leads to recruitment of beta-arrestins to the receptor complex, which in turn promotes receptor internalisation and uncoupling from the GPCRs [89]. The presence of $\mathrm{S}_{1} \mathrm{PR}_{1}$ is essential for egress of lymphocytes from the lymph nodes into lymph, a process mediated by a concentration gradient of S1P. With S1PR 1 internalised and uncoupled, cells do not respond to this gradient and remain within the lymph nodes (Fig. 4) [89].

As well as slowing T-cell egress, interaction of S1P with $\mathrm{S}_{1 \mathrm{PR}_{1}}$ also influences T-cell differentiation, affecting the production of Th17 cells [89]. Th17 cells are considered key mediators of inflammation in MS, and S1P can act to promote the formation of Th17 cells via $\mathrm{S} 1 \mathrm{PR}_{1}$. Activation of an interleukin-6-dependent pathway enhances the polarisation of $\mathrm{CD}^{+}$cells to form Th17 cells. In addition, S1P acting at $\mathrm{S}_{1} \mathrm{PR}_{1}$ inhibits the function of regulatory $\mathrm{T}$ cells, by blocking the differentiation of precursor cells and the function of mature cells, and so reduces their suppression of Th17 formation [89]. Interestingly, immunophenotyping analyses have shown that fingolimod and siponimod induce a reduction in circulating CD4+ $\mathrm{T}$ cells, $\mathrm{CD} 8+\mathrm{T}$ cells (specifically a selective reduction of naïve and central memory $\mathrm{T}$ cells with a relative increase of peripheral effector memory T cells), as well as B cells, in patients with RRMS and SPMS, respectively [90-92]. Gene expression studies have also shown reductions in the expression of key inflammation-related genes with fingolimod in patients with RRMS 
a

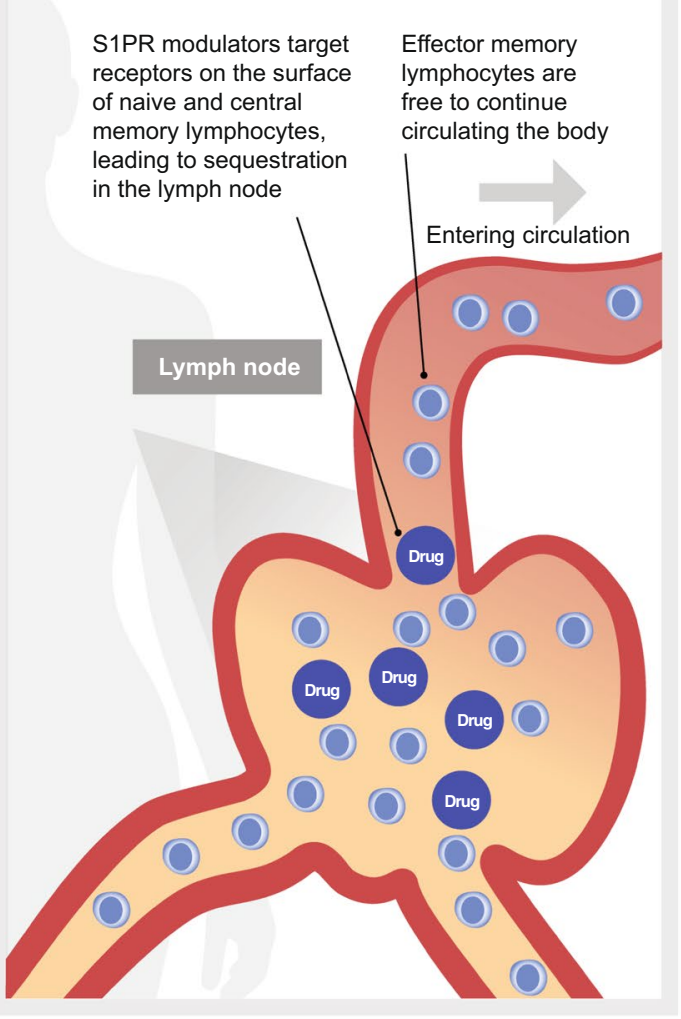

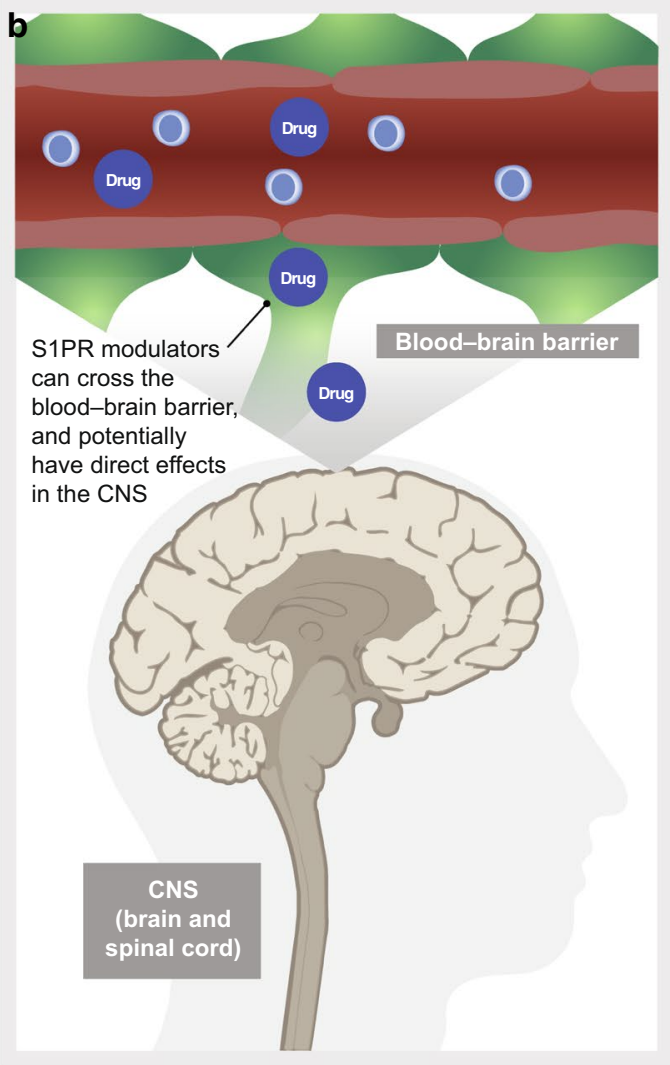

\section{C}

Neuron

Signalling

- $\mathrm{S}_{1 \mathrm{PR}_{1}}, \mathrm{~S} 1 \mathrm{PR}_{2}, \mathrm{~S}_{1 \mathrm{PR}_{3}}$ and $\mathrm{S}_{1} \mathrm{PR}_{5}$

- Neurogenesis, neural progenitor migration, survival, neurotransmission

Biological effects

- Reduced dentritic spine loss

- Restored neuronal function

- Protection from excitotoxic death

\section{Oligodendrocyte and} precursor cells

Signalling

- $\mathrm{S}_{1 \mathrm{PR}}, \mathrm{S} 1 \mathrm{PR}_{3}$ and $\mathrm{S} 1 \mathrm{PR}_{5}$

- Survival, migration, differentiation, process extension, retraction

Biological effects

- Promotion of OPC survival

- Effects on migration, differentiation and process dynamics

- Enhanced remyelination
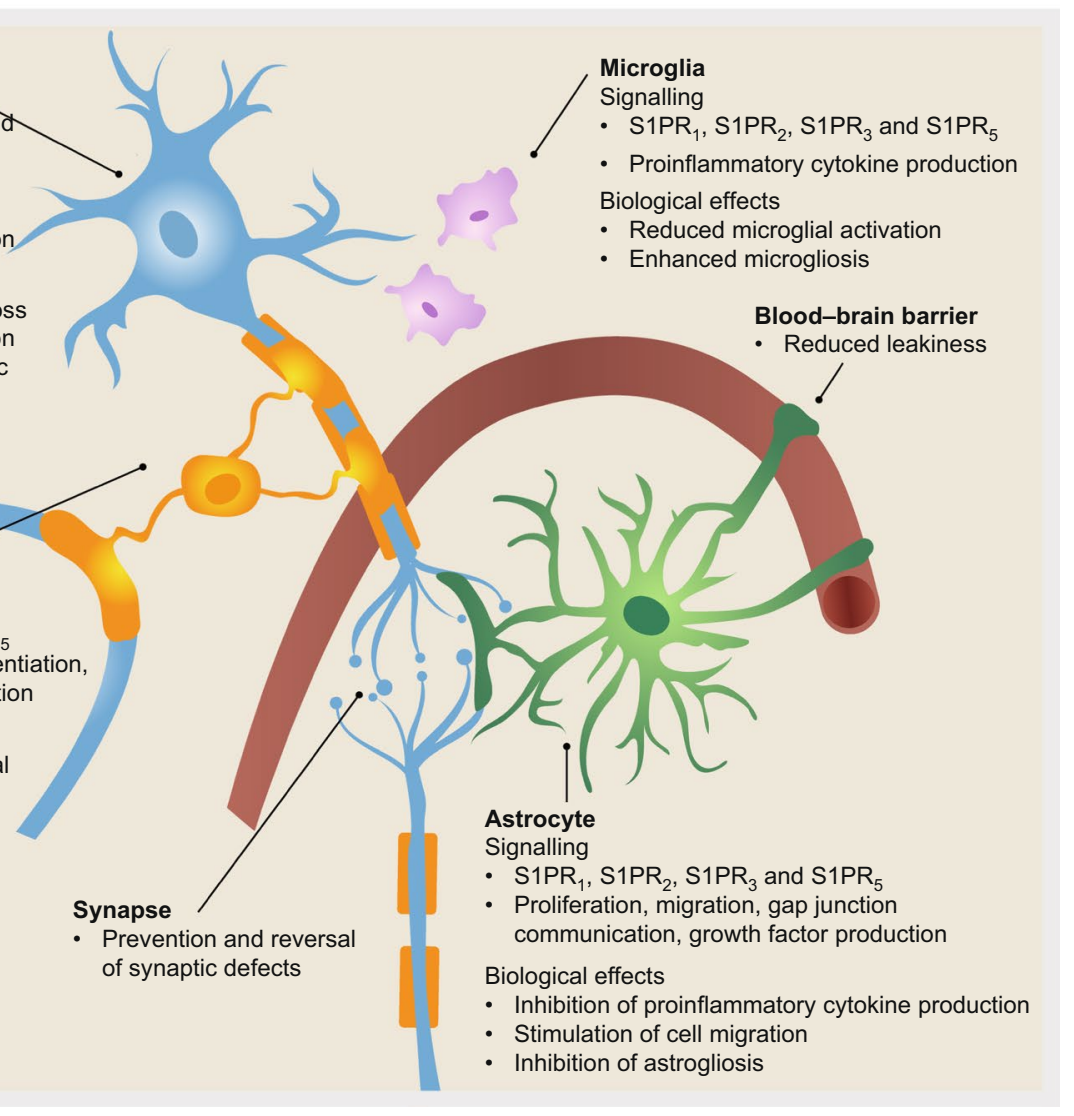
४Fig. 4 Peripheral and CNS mechanisms of action of S1PR modulators. a Binding of S1PR modulators to S1PR $\mathrm{PR}_{1}$ on central memory and naïve $T$ cells produces $S 1 \mathrm{PR}_{1}$ internalisation, resulting in cells that are unresponsive to $\mathrm{S}_{\mathrm{P}} \mathrm{PR}_{1}$-mediated signalling. Any new $\mathrm{S} 1 \mathrm{PR}_{1}$ being produced inside the cell will also be functionally antagonised until $\mathrm{S}_{1 \mathrm{PR}}$ modulation is removed. Therefore, activated central memory/naïve $\mathrm{T}$ cells do not leave the lymph node in response to S1P signals. By inhibiting their movement into the circulation, S1PR modulator treatment prevents these autoreactive cells from migrating into the CNS. In contrast, the levels of peripheral effector memory $\mathrm{T}$ cells are largely unaffected by S1PR modulators, thus preserving immunosurveillance and the capacity to respond to and contain locally invading pathogens. b S1PR modulators can also cross the blood-brain barrier (to varying degrees) and have direct effects on the S1PR subtypes expressed throughout the CNS. c Distribution, signalling and downstream biological effects of targeting S1PR subtypes in CNS cells. Information is from a composite review of the literature covering many different growth conditions in culture, developmental stages, disease states or animal models [49]. CNS central nervous system, $O P C$ oligodendrocyte precursor cell, S1P sphingosine 1-phosphate, SIPR sphingosine 1-phosphate receptor

[93] and with siponimod in patients with SPMS [91]. Additionally, siponimod was shown to shift the immune system toward an anti-inflammatory and suppressive homeostatic state through enrichment of regulatory $\mathrm{T}$ cells, transitional regulatory $\mathrm{B}$ cells and $\mathrm{B} 1$ subsets, possibly contributing to the clinical efficacy of siponimod in SPMS [91].

The time taken for lymphocyte counts to fall after treatment initiation, and the time taken for them to recover following treatment cessation, are summarised for various S1PR modulators in Table 1 [55]. The onset of the effects of S1PR modulators on lymphocyte trafficking is rapid, with effects observed within 4-16 h of administration. As might be expected, the time taken for lymphocyte counts to fall is broadly similar among the different compounds, while the time taken for them to recover appears to reflect differences in $t_{1 / 2}[55]$.

\subsection{S1PR Modulation and Immunocompetence}

Changes in the profile of circulating lymphocytes with S1PR modulators have led to concerns about a blunted responsiveness to vaccination in patients. Increasing reports of varicella zoster virus (VZV) infections in patients with MS are also a concern, given the effects of disease-modifying therapies on T-cell-mediated immunity. As of 31 May 2020, more than 303,600 patients had received fingolimod in a clinical trial or post-marketing setting, representing a cumulative exposure of more than 808,900 patient-years [94]. In clinical trials, rates of VZV infection with fingolimod were low, but were higher than with placebo; in the post-marketing setting, rates of VZV infection or herpes zoster with fingolimod were lower than in clinical trials, and serious or complicated cases of herpes zoster were uncommon [95]. To minimise the risk of VZV infection, patients without a confirmed history of chickenpox or without documentation of a full course of vaccination against VZV must be tested for antibodies to VZV before initiating fingolimod treatment. Vaccination against VZV in antibody-negative patients is recommended 1 month before starting fingolimod [96]. Current guidance from the Centers for Disease Control and Prevention also counsels that individuals not meeting specified criteria for evidence of VZV immunity should be vaccinated [97]. Patients taking fingolimod should avoid exposure to live attenuated vaccines while taking the drug and for 2 months after stopping treatment [96].

Studies with siponimod have so far indicated a limited effect on vaccination efficacy [98]. In a randomised, doubleblind, placebo-controlled study in healthy volunteers, siponimod showed no relevant effects on the antibody response to the pneumococcal polysaccharide vaccine (PPV-23), a T-cell-independent vaccination. Similarly, following the T-cell-dependent influenza vaccination, response criteria were met for three of the four antigens (H1N1, H3N2 and B-Massachusetts) in the siponimod and placebo groups, although titres were lower in the group receiving siponimod concomitantly with vaccination than in the groups receiving siponimod either before vaccination or before and after vaccination [98]. There are currently no clinical data available on the efficacy and safety of vaccinations in patients receiving ozanimod [10]; as with fingolimod [96] and siponimod [5], patients should be considered immune to VZV by documented infection (varicella or zoster), immunisation or serology before initiating treatment [10].

The use of S1PR modulators means that the immune status of patients cannot be monitored by CD4:CD8 ratios alone. S1P modulation affects circulating lymphocytes by inhibiting the egress of $\mathrm{T}$ cells from lymph nodes, but not the tissue distributions of lymphocytes. As such, circulating phenotypes do not necessarily reflect the tissue populations and cannot be used to ascertain host immunocompetence.

\section{S1PR Modulation and Neuroprotection in MS}

The distribution of S1PRs on cell types in the CNS and roles of S1P-mediated signalling are summarised in Fig. 4 [49]. $\mathrm{S}_{1 \mathrm{PR}}, \mathrm{S} 1 \mathrm{PR}_{3}$ and $\mathrm{S} 1 \mathrm{PR}_{5}$ subtypes are located on neurons, astrocytes, microglia, oligodendrocytes and oligodendrocyte precursor cells (OPCs), while $\mathrm{S}_{1} \mathrm{PR}_{2}$ is found on neurons, astrocytes and microglia but not oligodendrocytes or OPCs. The roles of S1P-mediated signalling differ between the cell types, and include proliferation, migration, survival and the production of cytokines and growth factors [49].

Most of the published data characterising the CNS effects of S1PR modulators currently come from cellular and animal studies of fingolimod (summarised in Fig. 4) or siponimod, 
and these have demonstrated a range of effects including actions on astrocytes and microglia, and involvement in remyelination and repair $[49,99,100]$. The most common animal model for MS is EAE, which involves induced demyelination of the nervous system and is the most common model used to study S1PR modulators.

\subsection{Effects on Astrocyte and Microglial Biology}

$\mathrm{S}_{1 P R_{1}}$ levels on astrocytes are increased in MS, and functional antagonism of $\mathrm{S}_{\mathrm{PPR}}$ with fingolimod is associated with reduced levels of astrogliosis [71, 86, 87]. Fingolimod activity was shown to require $\mathrm{S}_{\mathrm{PPR}}$ on astrocytes in EAE models [71]. In EAE, fingolimod reduced clinical scores and peripheral blood lymphocyte counts when administered following EAE onset in control mice. However, in mice engineered to be conditionally null for $\mathrm{S}_{\mathrm{PR}}$ in glial fibrillary acidic protein (GFAP)-expressing astrocytes, EAE was less severe and became unresponsive to fingolimod, despite maintenance of fingolimod-dependent lymphocyte depletion. Histological analysis showed prominent astrogliosis (identified by GFAP immunoreactivity) in EAE controls, which was prevented or reduced by fingolimod and by the genetic deletion of $\mathrm{S}_{1} \mathrm{PR}_{1}$ on astrocytes, suggesting a role for $\mathrm{S}_{1} \mathrm{PR}_{1}$ in astrogliosis in MS [71].

Another study involving EAE mice showed that the combination of fingolimod and neural stem cells significantly reduced astrogliosis in the secondary progressive stage of relapsing-remitting EAE, as assessed by GFAP immunoreactivity. Furthermore, fingolimod significantly reduced the expression of astrocyte genes, including GFAP, vimentin and $\mathrm{N}$-cadherin, in neural stem cells in vitro under differentiation conditions [101]. Fingolimod was also associated with reduced astrogliosis in a cuprizone mouse model (where copper chelation causes demyelination, apoptosis of mature oligodendrocytes and activation of CNS inflammation but leaves the BBB intact, and so excludes any contribution of T-cell infiltration from the periphery [102]). In this mouse model, the accumulation of reactive astrocytes and microglia seen with cuprizone-induced demyelination was reduced by fingolimod [86]. In addition, fingolimod reduced the formation of immediate-early astrocytes in EAE mice, a subpopulation of inflammatory astrocytes defined initially by c-Fos activation in vivo using a green fluorescent protein-tagged reporter [103]. Immediate-early astrocytes are the earliest, and most prominent, cell type to respond to EAE induction, and the numbers of these astrocytes correlate with disease severity in vivo [103], suggesting that they could represent a new therapeutic target in MS.

Fingolimod administration reduced the expression of proinflammatory cytokines and chemokines in astrocytes isolated from mice following the induction of EAE [104]. In human astrocyte cultures in vitro, the expression of a range of proinflammatory chemokines, cytokines and neurotoxic factors was decreased with fingolimod, and fingolimod also up-regulated the expression of interleukin-10, a neuroprotective factor. Analysis showed that these effects were mediated in part by the suppression of NF- $\mathrm{KB}$ signalling by fingolimod [104]. Cell culture studies also suggest that fingolimod may regulate specific neuroinflammatory responses by desensitising astrocytes to stimuli through the natural S1P ligand signalling at external S1PRs, while sustaining cellular effects independent of new surface S1PR activation [105]. For example, fingolimod inhibited the protein kinase R-like endoplasmic reticulum kinase (pERK1/2) signalling induced by S1P and reduced the proliferative responses to S1P in astrocytes [105]. In addition, fingolimod inhibited the release of intracellular calcium when stimulated by interleukin-1beta, demonstrating that fingolimod maintained a functional cellular response [105].

Other studies have also reported beneficial effects of siponimod on astrogliosis and microgliosis. In EAE mice, intracerebroventricular infusion of siponimod attenuated astrogliosis and microgliosis, and reduced striatal lymphocyte infiltration [106]. Siponimod reduced grey matter inflammation in EAE mice, with analysis of immunofluorescence showing a reduction in astrogliosis and microgliosis in the striatum compared with the vehicle control. In addition, siponimod reduced lymphocyte infiltration detected in coronal striatal sections [106]. In a model of subpial pathology, where proteolipid protein-primed Th17 cells were transferred into EAE mice, siponimod significantly reduced EAE and subpial pathology concurrent with a selective reduction in Th17 cytokine production in the transferred T cells [107]. In another study, oral siponimod treatment decreased macrophage infiltration/microglia activation in the spinal cord in mice with chronic EAE [108]. Inflammation and demyelination were also reduced along with disease symptoms compared with the vehicle control [108]. A mouse model of traumatic brain injury reported benefits, wherein siponimod reduced astrocytosis, microglial activation and cytokine release, decreased CD4+ and CD8+ T-cell activation and reduced lesion area [109].

Fingolimod and siponimod also appear to mitigate synaptic neurodegeneration in EAE mice [106]. Inflammationdependent synaptopathy in EAE mice involves reduced inhibitory GABA signalling and results in neurodegeneration. Intracerebrovascular administration of siponimod significantly ameliorated the reduction in inhibitory GABA signalling in the striatum of EAE mice [106]. Siponimod administration also reduced striatal astrogliosis and microgliosis, and was associated with improved EAE clinical scores [110]. When directly administered into the CNS of EAE mice with distinct grey- and white-matter lesions, siponimod-treated mice showed partial restoration of cortical neuronal circuit function compared with untreated, 
lesioned controls, suggesting that siponimod may exert neuroprotective effects in the CNS, independent of peripheral effects [111].

A recent study of ex vivo brain slice cultures from EAE mice and a Th1 cytokine-activated EAE-like microglial cell line suggests that ozanimod may also exert direct neuroprotective effects and attenuate local inflammatory responses [112]. Ozanimod treatment ameliorated EAE-driven striatal glutamatergic synapse alterations in an $\mathrm{S}_{1} \mathrm{PR}_{1}$-dependent manner and lowered the expression level of pro-inflammatory markers in EAE brain slices and microglial cell cultures [112].

The involvement of the $\mathrm{S}_{\mathrm{PR}}$ subtype in astrogliosis, as noted in the sections above, was demonstrated using genetic deletion studies where it ameliorated the development of EAE in mice [71]; similarly, another recent study in EAE mice showed that the astrocyte-specific genetic removal of $\mathrm{S}_{1 \mathrm{PR}}$ reduced both immediate-early astrocyte numbers and disease severity [103]. However, other S1PR subtypes may also have a role: a recent study indicated that protection of astrocytes by fingolimod against certain types of neuroinflammation was mediated by its interaction with $\mathrm{S}_{1} \mathrm{PR}_{3}$ [113]. Analysis showed that down-regulation of $\mathrm{S}_{\mathrm{PR}}$ in astrocytes using an antisense oligonucleotide abolished the protective effects of fingolimod against oxygen-glucose deprivation injury and reversed the reduction in pro-inflammatory cytokine release seen with fingolimod [113].

\subsection{Effects on Remyelination and Repair}

Interaction of fingolimod and siponimod with $\mathrm{S}_{1} \mathrm{PR}_{5}$ on oligodendrocytes has been associated with protection against demyelination and the promotion of remyelination in both in vitro and in vivo animal studies [77, 99, 114-116]. A cell culture study showed that, following demyelination, fingolimod exposure was associated with increases in the biochemical and morphological markers of remyelination [114]. Siponimod also increased the levels of myelin basic protein (a biochemical marker of remyelination), whereas no

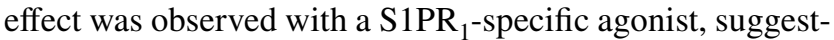
ing the involvement of $\mathrm{S}_{1} \mathrm{PR}_{5}$ in the remyelination process in vitro [114]. Another in vitro study showed that fingolimod enhanced remyelination and process extension of OPCs and mature oligodendrocytes [117], events that are thought to be important for remyelination.

Fingolimod enhanced endogenous myelin repair in a mouse model of local demyelination induced by lysolecithin [118]. Fingolimod decreased the extent of demyelinated area when administration was started prior to lysolecithin induction, and continued administration after induction increased the number of OPCs and oligodendrocyte lineage cells in the lesion, which are important for remyelination. While this is a model for demyelination, it is notable that lysolecithin is also known as lysophosphatidylcholine, a precursor to the major lysophospholipid LPA that modulates myelination in a receptor-dependent fashion [119, 120]. In addition, fingolimod was associated with an increase in remyelinated axons and newly produced myelinating cells [118]. Fingolimod can also induce OPC process extension and enhance oligodendrocyte cell survival in a human cell culture model, both mechanisms necessary for remyelination [121].

In a study involving neural stem cells, fingolimod protected their survival in vitro, and enhanced their development into mature oligodendrocytes [101]. Further investigation using specific $S 1 \mathrm{PR}_{1}$ and $\mathrm{S}_{1} \mathrm{PR}_{5}$ antagonists suggested that fingolimod acts through $\mathrm{S}_{1 \mathrm{PR}_{5}}$ to enhance the differentiation of neural stem cells into oligodendrocytes. Furthermore, in mouse EAE, fingolimod improved the incorporation and survival of transplanted neural stem cells in the CNS and promoted their development into oligodendrocytes and OPCs, thus promoting remyelination [101].

Enhanced remyelination was observed with siponimod under functional antagonist conditions using an in vivo Xenopus tadpole model [116]. Following induced demyelination, a marked increase in myelinated fibres was observed with siponimod compared with the spontaneous remyelination control. Remyelination was improved by a selective $\mathrm{S}_{\mathrm{PPR}}$ agonist, but not by a selective $\mathrm{S}_{\mathrm{PRR}}$ agonist, and siponimod was ineffective following deletion of $\mathrm{S}_{1} \mathrm{PR}_{5}$ by gene editing, indicating the importance of $\mathrm{S}_{\mathrm{PR}}$ in the promyelinating effects of siponimod [116].

In the cuprizone mouse model of demyelination, siponimod decreased axon demyelination and oligodendrocyte cell death [115]. Siponimod was associated with a decrease in axon damage and a reduction in the loss of myelin proteins and mature oligodendrocytes of $25 \%-40 \%$ compared with the vehicle control during the demyelination period. Furthermore, electron microscopy showed a $25 \%$ increase in the number of myelinated axons during remyelination. In addition, there was a decrease in microglia/macrophages with siponimod, although astrocyte numbers increased [115]. In organotypic cerebellar slice cultures, siponimod reduced demyelination induced by lysophosphatidylcholine (lysolecithin) and by psychosine, although it had only a modest effect in reducing the increase in the proinflammatory cytokine interleukin-6 stimulated by lipopolysaccharide or tumour necrosis factor-alpha/interleukin-17 in astrocyte and microglia cell cultures [77].

\subsection{Effects on Brain-Derived Neurotrophic Factor}

Both fingolimod and siponimod have been shown to increase the levels of brain-derived neurotrophic factor (BDNF), a neurotrophin involved in neuronal differentiation and survival, in neuronal cultures and in brain tissue in both healthy and EAE mice $[122,123]$. Fingolimod and siponimod each 
increased BDNF levels in cortical neuronal cultures, while in healthy mice, daily administration of either fingolimod or siponimod led to increased BDNF levels in the cortex, hippocampus and striatum when compared with saline [123]. No increase in BDNF was observed in the cerebellum with siponimod compared with controls (fingolimod was not tested). Increased BDNF levels in the cortex, hippocampus and striatum (but not the cerebellum) were also observed with a specific $S 1 P R_{1}$ agonist, indicating that treatment effects were at least in part mediated via the $S 1 \mathrm{PR}_{1}$ subtype [123].

In EAE mice, fingolimod treatment significantly increased BDNF protein levels in the forebrain, midbrain and cerebellum compared with vehicle controls, although levels in the spinal cord were not affected [122]. Fingolimod treatment, administered once EAE was established, ameliorated the progressive reductions in cerebellum and striatum volume seen in vehicle-treated EAE mice, resulting in cerebellum and striatum volume profiles similar to healthy control animals. By contrast, the approved MS therapy teriflunomide showed no significant improvements in any brain volume measures in EAE mice compared with controls [122].

\section{S1PR Modulation and Cardiac Effects}

As discussed above, cardiac effects associated with treatment initiation appear to be mediated by transient agonism of S1PR 1 and thus, all agents that engage this receptor will have some form of cardiac effect. The possible involvement of $\mathrm{S}_{1} \mathrm{PR}_{3}$ in humans remains unclear, and even though endeavours to develop new modulators with low affinity for $\mathrm{S}_{1 \mathrm{PR}_{3}}$ have been extensive, minimising $\mathrm{S}_{1} \mathrm{PR}_{3}$ binding does not prevent first-dose cardiac effects [30, 68]. For example, siponimod and ozanimod, which target $\mathrm{S}_{1} \mathrm{PR}_{1}$ and $\mathrm{S} 1 \mathrm{PR}_{5}$ but have only low affinity for $\mathrm{S}_{1} \mathrm{PR}_{3}$, are associated with chronotropic effects at initiation that are manageable via dose titration [63, 65, 78, 124].

For S1PR modulators with short half-lives and without long half-lived active metabolites such as siponimod and ponesimod $[67,78]$, there exists a potential for 'inadvertent first-dose effects' following relatively brief treatment interruptions. In case of treatment interruption, therapy should be reinitiated with dose titration [5].

\section{S1PR Modulation and Endothelial Effects}

\subsection{Macular Oedema}

S1PR modulators are known to produce endothelial-mediated abnormalities manifesting as a low incidence of early macular oedema $(0.2 \%-2.0 \%$ depending on the patient population, agent and dose; Online Resource Table 2). Macular oedema has significant additional risk with age, and with maculopathies from diabetes or uveitis.

\subsection{Blood Pressure Regulation}

Receptor subtypes $\mathrm{S}_{1} \mathrm{PR}_{1}$ and $\mathrm{S}_{1 \mathrm{PR}_{3}}$ also play a pivotal role in blood pressure regulation, including endothelial barrier function $[26,52,54]$. Functional antagonism of $\mathrm{S}_{\mathrm{PR}}$ by fingolimod (and other S1PR modulators) might therefore be expected to herald changes in blood pressure, but based on studies to date, effects in humans appear to be mild at most [55]. If hypertension is observed, it is typically mild and rarely dramatic, although in a few cases it has been associated with posterior reversible encephalopathy syndrome [96]. Small transient decreases in blood pressure have been reported in clinical trials in patients with MS following the initiation of fingolimod treatment; these initial reductions started to attenuate by $6 \mathrm{~h}$ after dosing [125]. Small mean increases in systolic and diastolic blood pressure $(3 \mathrm{mmHg}$ and $1 \mathrm{mmHg}$, respectively) were observed with long-term treatment in fingolimod clinical trials [126]. Increases in blood pressure were apparent at 2 months after starting therapy and then increased over the following 4 months before stabilising [126]. As with cardiac effects, these may in part reflect action of the drug at the receptors.

\subsection{Blood-Brain Barrier}

Changes in the BBB have long been recognised as an important part of the pathophysiology of MS. Autoreactive lymphocytes bind to the BBB endothelium before extravasation into the CNS, where they lead to the characteristic neuroinflammatory events. While BBB disruption is often seen around lesions in magnetic resonance imaging, it is not limited to lesion activity; tight junction (TJ) protein pathology (for example of occludin, claudin-5 and zona occuldens-1) is apparent throughout the $\mathrm{BBB}$, including in active lesions, in non-active chronic lesions and normal-appearing white matter, affecting BBB integrity [127-131]. Shedding of $\mathrm{TJ}$ proteins into the serum is thought to be indicative of BBB disruption in stroke, intracranial haemorrhage and MS [132-134]; however, serum TJ concentrations were significantly reduced in patients with MS after 12 months of fingolimod treatment [134]. While there are no patient data on the effect of other S1PR modulators on BBB integrity in MS, siponimod has also been shown to have beneficial effects on occludin and zonula occludens- 1 in a mouse model of traumatic brain injury [109], suggesting that positive effects on $\mathrm{TJ}$ and BBB integrity may prove to be a class effect of S1PR modulators. 


\section{Metabolism of S1PR Modulators and Clinical Implications}

Patients experiencing excess S1P modulatory effects can experience lymphopenia, which when excessive $(<200$ lymphocytes per $\mu \mathrm{L}$ ) under other scenarios, raises safety concerns including its impact on the total white blood cell count, which can elicit concerns in some healthcare professionals. However, careful review of events in clinical trials indicated that severe lymphopenia is not a risk, is manageable with dose adjustment or interruption, and is not associated with serious adverse events $[55,135,136]$.

Fingolimod has a relatively simple metabolism requiring phosphorylation for activity and slow rates of elimination. It can be eliminated by hepatic metabolism, enhanced slightly by potent CYP3A4 enzyme inducers (such as carbamazepine) and blocked significantly by powerful CYP3A4 inhibitors, such as ketoconazole. In practice these effects are not noticed.

Clearance of siponimod is normally dependent on CYP2C9 metabolism, with a minor contribution of CYP3A4. Because of CYP2C9 polymorphisms, a precision dosing plan was developed during the regulatory process in the USA using pharmacokinetic data, principally driven by the presence of severe lymphopenia (which it was felt desirable to avoid). Use in poor CYP2C9 metabolisers (CYP2C9 $* 3 / * 3$ ) is contraindicated, and intermediate CYP2C9 metabolisers $(\mathrm{CP} 2 \mathrm{C} 9 * 1 / * 3$; $\mathrm{CP} 2 \mathrm{C} 9 * 2 / * 3)$ receive half the dose of normal metabolisers. Although CYP3A4 normally has a minor contribution to termination of siponimod action, this pathway is highly inducible by agents commonly used in neurology patients, including barbiturates, carbamazepine, phenytoin and similar agents, and can halve circulating concentrations of siponimod [5]. In addition, a number of agents potentially inhibit CYP2C9, which could increase exposure to siponimod [5]. Appropriate therapeutic substitutions and dosing for patients on this drug can address these issues, and the availability of easily reduced dosing strategies may be beneficial in exceptional circumstances.

Ozanimod metabolism is complex and has only recently been elucidated as compared with other, better studied, S1PR modulators (see Sect. 4.1 for details). Most importantly, the two key biotransformations involve CYP3A4 and MAO-B (which is expressed in the CNS) [64]. As discussed above, CYP3A4 both activates ozanimod and inactivates ozanimod [64], and may terminate the bulk of the activated metabolites. CYP3A4 inducibility could shorten the clearance of the active metabolites dramatically, reducing their therapeutic actions. Activated metabolites are terminated by CYP2C8 [10], which has few significant interactions, although co-administration of strong CYP2C8 inhibitors (such as gemfibrozil) or inducers (such as rifampin) are not recommended owing to the potential for inadvertent increases or decreases in exposure to the active metabolites, respectively. Concomitant use of MAO inhibitors is also contraindicated [10]. Ponesimod has so far been felt to have a relatively simple and uncomplicated biotransformation; drug interactions of importance have not yet been identified.

\section{Clinical Efficacy of S1PR Modulators}

An overview of study designs, and safety and efficacy findings with fingolimod, siponimod and other S1PR modulators in clinical trials of patients with MS are provided in Table 2 and in Online Resource Tables 2 and 3. The majority of these studies have involved patients with RMS, with only siponimod having completed a Phase 3 trial in patients with SPMS, to date [9]. The Phase 2 and Phase 3 clinical trials assessing S1PR modulators in patients with MS are as follows: fingolimod has been evaluated in three RRMS Phase 3 trials, two of which were placebo-controlled (FREEDOMS, FREEDOMS II) and one of which compared fingolimod with interferon beta-1a TRANSFORMS) [72-74], while siponimod has been assessed in the placebo-controlled Phase 2 BOLD trial and extension, in patients with RRMS $[78,137]$ and in the placebo-controlled Phase 3 EXPAND trial in patients with SPMS [9]. Evaluation of ozanimod has involved a placebo-controlled and active-controlled (vs interferon beta-1a) combined RMS Phase 2/3 trial (RADIANCE) $[12,138,139]$ and an active-controlled Phase 3 trial versus interferon beta-1a (SUNBEAM) in patients with RMS [11, 140, 141], while the assessment of ceralifimod in patients with RRMS has involved a placebo-controlled Phase 2 study (DreaMS) [142]. Ponesimod has been assessed in a placebocontrolled Phase 2b study (NCT01006265) [67], and a completed active-controlled Phase 3 trial versus teriflunomide (OPTIMUM) in patients with RRMS (NCT02425644), while the placebo-controlled Phase 2 MOMENTUM study and extension have evaluated amiselimod in patients with RRMS [143, 144].

The results of the clinical trials in RRMS appear to be fairly consistent across the different S1PR modulators, indicating the effectiveness of this mechanism of action in patients with MS. As there are no head-to-head data comparing the different S1PR modulators, direct efficacy or safety comparisons cannot be made. However, fingolimod, siponimod, ozanimod and ponesimod have all demonstrated reductions in annualised relapse rates and lesion activity (gadolinium-enhancing T1, new/enlarging T2) in their respective trials. Reductions in the proportions of patients with confirmed 3- and/or 6-month disability progression and reductions in the rate of brain volume loss (BVL) have been reported for fingolimod and ozanimod. Disability progression and BVL were not assessed in the BOLD study of 


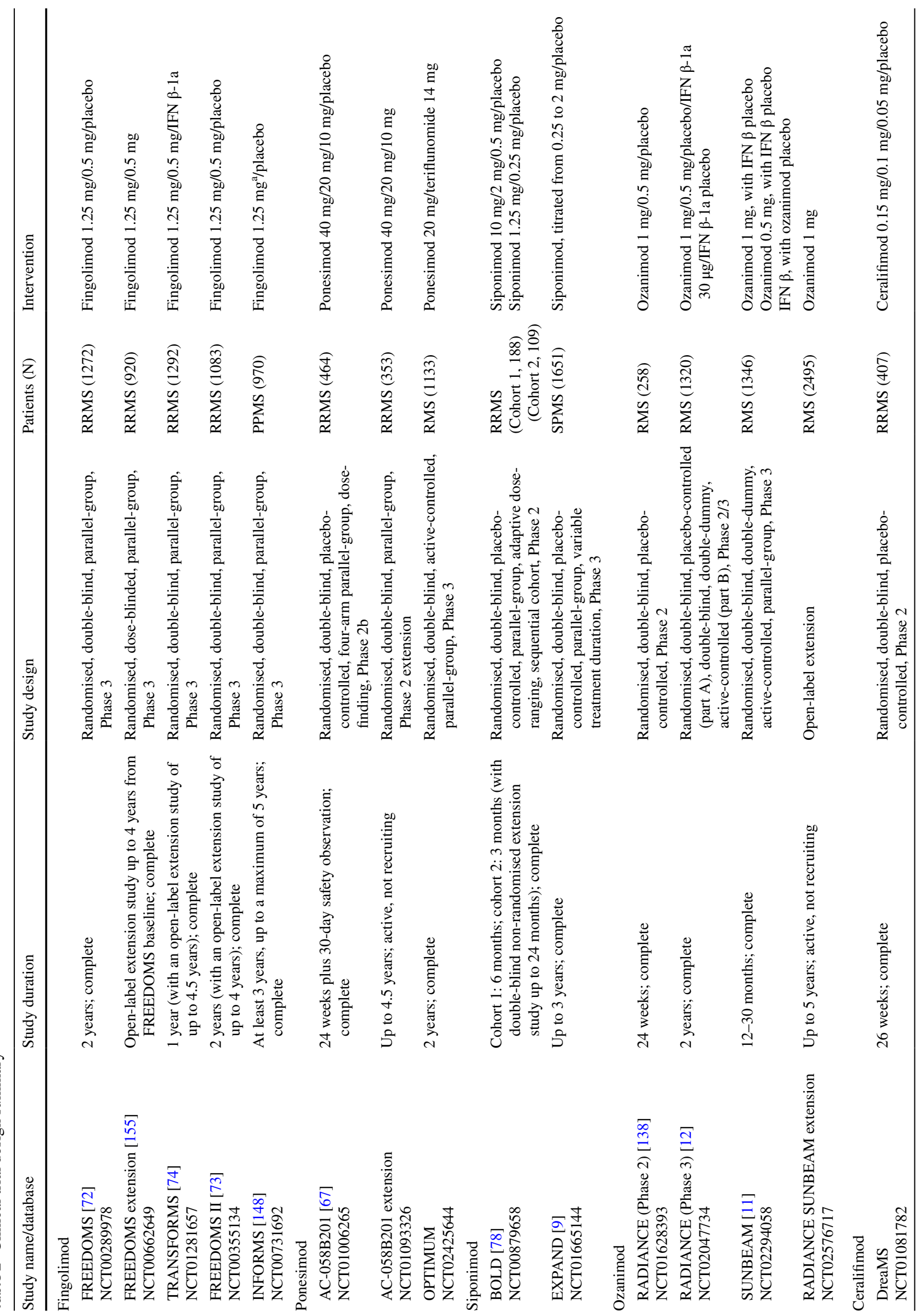




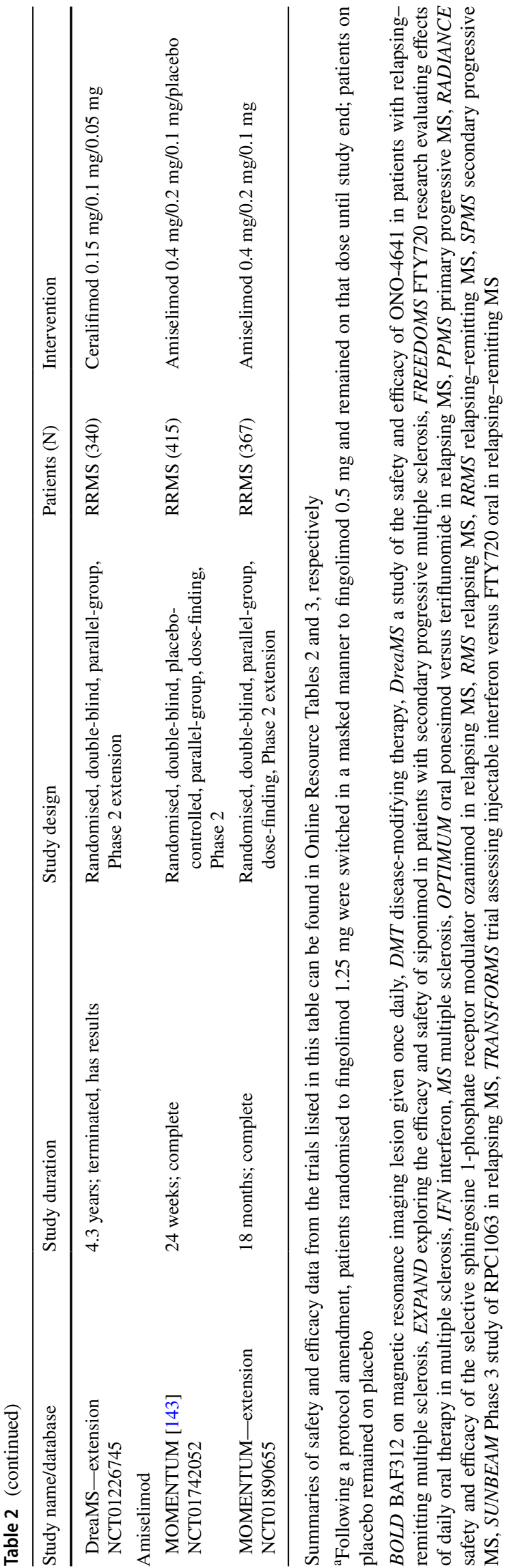

siponimod in patients with RRMS, but siponimod significantly reduced the risk of disability progression and the rate of BVL in patients with SPMS in EXPAND, together with reductions in annualised relapse rates and lesion activity [9]. Indeed, siponimod is currently the only therapy in MS that has demonstrated efficacy in the SPMS patient population.

Earlier in this review, the considerable evidence from cell and animal models of MS of direct effects on the CNS and on neurodegeneration with fingolimod and siponimod was discussed. The evidence for parallel effects in patients is limited, but there is some indication of S1PR modulation having some efficacy on progressive, neurodegenerative disease in MS. Unlike natalizumab, where the primary mechanism of action is also to prevent lymphocytes from accessing the CNS, fingolimod reduced the rate of BVL in patients with RRMS [72-74]. While it is likely that the effects on inflammatory processes in the CNS contribute to the effect on BVL, the potential effects of S1PR modulation on the CNS through $\mathrm{S}_{1} \mathrm{PR}_{1,5}$ may also play a role. Reductions in the rate of cortical grey matter volume loss and thalamic volume loss observed in patients receiving fingolimod, siponimod or ozanimod suggest some efficacy in managing neurodegenerative aspects of the disease [145-147].

Evidence of disease-modifying effects in patients with more progressive forms of MS would also indicate a role for S1PR modulation in this patient group. Fingolimod was trialled in patients with primary progressive MS in INFORMS [148]. The study did not meet the primary endpoint, with no benefit shown with fingolimod in terms of disability progression or BVL versus placebo. However, INFORMS succeeded in recruiting a population with progressive MS and very-low inflammatory activity. In a post hoc analysis, a positive effect on BVL was observed in the subgroup of progressive patients who had some inflammatory CNS activity at baseline [149]. The reasons for this are not known, but may reflect the action of fingolimod on inflammatory disease in MS. It may also suggest that in most patients, disease progression was too advanced for therapeutic efficacy, analogous to Alzheimer's disease trials. A nuclear transcriptome analysis of single cells extracted from post-mortem prefrontal cortex samples from patients who had RRMS or SPMS suggests that sphingosine kinase 1 and 2 expression may be significantly lower in SPMS [150]. A reduction in the phosphorylation of fingolimod in the CNS of patients with progressive disease may thus contribute to the lack of efficacy of fingolimod in this patient group. By comparison, reductions in BVL over 12 and 24 months, compared with placebo, were significant with siponimod in patients with SPMS in EXPAND [9], and sensitivity analyses suggest that effects on disability progression were largely independent of the effect on relapses [9, 151], consistent with siponimod's independence from sphingosine kinases and likely direct CNS activities. Post hoc analyses of the time to 
sustained disability progression to an Expanded Disability Status Scale (EDSS) score of 7 or more in the EXPAND patient population suggested that siponimod significantly reduced the risk of progression to this point compared with placebo, and of particular clinical relevance, increased the median time before patients had transitioned to the use of a wheelchair [152]. In addition, assessment of neurofilament levels in blood samples from patients with relapsing and non-relapsing forms of SPMS suggested that siponimod reduced neuronal damage compared with placebo [153]. Together, the clinical evidence suggests that S1PR modulators may have a direct effect on neurodegenerative processes in MS; however, additional analyses and data from longerterm studies are needed to confirm this mechanism of action.

With regard to safety signals, all the S1PR modulators appeared to be relatively well tolerated compared with their on-study comparators. The most common adverse events were similar across the drug class, including headache, nasopharyngitis, urinary tract infections and respiratory infections. As of 31 May 2020, more than 303,600 patients had received fingolimod in a clinical trial or post-marketing setting, representing a cumulative exposure of more than 808,900 patient-years [94]; however, the drug has been associated with some rare but serious events. Cryptococcal infections, including cases of fatal cryptococcal meningitis and disseminated cryptococcal infections, and cases of progressive multifocal leukoencephalopathy have occurred, generally in patients receiving treatment for more than 2 years. Life-threatening disseminated VZV and herpes simplex infections, including cases of encephalitis and multiorgan failure, have been reported, as have cases of Kaposi's sarcoma [96]. Whether such events will prove to be a class effect relies on accumulation of more clinical evidence from other drugs, but it is reasonable to be concerned and to monitor for this in the long term among all S1PR modulators.

Unanticipated first-dose cardiac effects are a known but uncommon effect with fingolimod, with the vast majority of events being benign and resolving without intervention [154]; first-dose cardiac effects were also seen with ponesimod [67]. The EXPAND study of siponimod was conducted in an older, progressive population compared with other S1PR modulator trials (patients with SPMS: baseline mean age was 48 years and mean EDSS score was 5.4, with $56 \%$ of patients having an EDSS score $\geq 6.0$ ) and allowed certain patients with cardiovascular risks to participate in the study [9]. On the other hand, the two pivotal ozanimod trials, RADIANCE Phase 3 and SUNBEAM, enrolled patients with RMS who were typically younger and with less disability (mean ages at baseline were 35.5 and 35.6 years, respectively, and mean baseline EDSS scores were 2.5-2.6 and 2.6-2.7, respectively, depending on randomisation group). While the exclusion criteria of the ozanimod trials were very similar to EXPAND in terms of cardiovascular risk, the ozanimod trials may have been somewhat more restrictive; patients with conduction abnormalities or cardiac conditions that in the opinion of the treating investigator could jeopardise the patient's health were excluded, as were patients with pre-existing stable cardiac conditions without clearance from a cardiologist [10-12]. Irrespective of these differences, dose titration effectively mitigated cardiac chronotropic effects with both drugs and the resulting label contraindications for ozanimod and siponimod with regard to the cardiovascular histories of patients are nearly identical $[5,10]$. With siponimod, the majority of patients can initiate treatment without the need for monitoring and FDO is recommended only for patients with sinus bradycardia, first- or second-degree (Mobitz type I) atrioventricular block, or a history of myocardial infarction or heart failure [5]. With ozanimod, no monitoring at treatment initiation is required but cardiologist consultation is suggested for patients with conduction abnormalities [10]. Consultation is also suggested for both siponimod and ozanimod in cases where patients require concomitant use with other drugs that decrease heart rate $[5,10]$.

Owing to the differential pharmacokinetic response to siponimod in patients with CYP2C 9 genotypes $1 / 3$ or $2 / 3$, genotyping of patients must be performed and treatment initiated at the relevant maintenance dose $(1 \mathrm{mg}$ for CYP2C $1 / 3$ or $2 / 3$ patients; $2 \mathrm{mg}$ for all other patients), according to the prescribing information [5]. Ozanimod is transformed into multiple active metabolites, two of which are principally responsible for biological activity (CC112273 and CC1084307; 73\% and 15\%, respectively, as noted above), with a small contribution from ozanimod itself [64]. Whether the pharmacokinetics of ozanimod affects its efficacy or safety profile in the longer term remains an open question.

\section{Discussion/Conclusion}

Via signalling through five distinct lysophospholipid GPCR subtypes, $\mathrm{S}_{1 \mathrm{PR}_{1}}$ to $\mathrm{S}_{1} \mathrm{PR}_{5}$, the physiological and pathophysiological roles of S1P are wide-ranging. Investigation of the S1P receptor pathway has proved instrumental in developing a novel class of therapies for patients with MS. The first S1P receptor modulator to be approved for use in patients with relapsing forms of MS, and more recently in paediatric patients with MS [96], fingolimod, has been shown to be a useful treatment option.

Indeed, by 31 May 2020, it was estimated that more than 303,600 patients had been treated with fingolimod, corresponding to approximately 808,900 patient-years of clinical trial and post-marketing exposure [94], with clinical trials demonstrating reductions in rates of relapse, lesion activity and BVL in patients with RRMS, but more limited effects 
in progressive forms of disease. Owing to the affinity of fingolimod to most of the S1PR subtypes, including S1PR cardiac chronotropic effects at first dose were expected, as they should be for all S1PR modulators engaging S1PR . Notably, retrospective assessment of a large-scale, realworld dataset of over 20,000 FDO procedures has shown that effects at first dose were generally mild in most patients and complications were rare [154].

The chemical structural refinements in second-generation S1PR modulators avoided the need for in vivo phosphorylation for activity. Together with the adoption of dose-titration strategies, siponimod and ozanimod do not require FDO for the majority of patients; for siponimod it is only recommended for those with a history of certain cardiac comorbidities [5] and the chronotropic effects of ozanimod appear to be similarly mild $[11,12]$. The improved pharmacodynamics and subtype specificity for $\mathrm{S}_{1} \mathrm{PR}_{1}$ and $\mathrm{S} 1 \mathrm{PR}_{5}$ may also contribute to improved bioavailability and potentially greater CNS effects compared with fingolimod, although only siponimod has so far demonstrated efficacy in SPMS $[9,147,152]$, contrasting with the absence of clinical effects with fingolimod in primary progressive MS [148]. Functional differences between fingolimod and siponimod are supported by nuclear transcriptome analysis of human primary astrocytes treated with either phosphorylated fingolimod or siponimod that revealed differential effects where siponimod up- or down-regulates many fewer genes than does fingolimod [150]. These observations support differential effects amongst chemically distinct S1PR modulators.

In summary, S1PR modulators have complex effects on S1PRs and the S1P signalling pathway. The intricate interplay of S1PR subtype specificity, functional antagonism and agonism of receptors, and activation requirements dictates their pharmacokinetics, bioavailability and ultimately their clinical profile. In MS, the mechanisms of action of S1PR modulators have positive effects with regard to immune cell trafficking and likely direct CNS effects, which may lead to a range of efficacy signals including neuroprotection; second-generation modulators with good bioavailability, high specificity for and activity at $\mathrm{S}_{\mathrm{PR}}$ and $\mathrm{S}_{1} \mathrm{PR}_{5}$ may mitigate some side effects associated with this drug class while maximising potential clinical benefit, including in progressive forms of MS.

Acknowledgements Medical writing assistance was provided by $\mathrm{Dr}$ Ian M. Williams of Oxford PharmaGenesis, Oxford, UK, and supported by Novartis Pharmaceuticals Corporation, East Hanover, NJ, USA. We would like to thank Dr Erica Andreozzi, Dr Elizabeth Hur and Dr Monica Keyport of Novartis Pharmaceuticals Corporation for their constructive feedback during the development of this review.

\section{Declarations}

Conflict of interest Jerold Chun has received consulting fees or research support from Abbott, AbbVie, Amira, Arena Pharmaceuticals, Biogen Idec, BiolineRX, Blade Therapeutics, Brainstorm Cell Therapeutics, Celgene, GlaxoSmithKline, Inception Sciences, Johnson \& Johnson, Merck, Mitsubishi Tanabe, Novartis, Ono Pharmaceuticals, Pfizer, SKAI Ventures and Taisho Pharmaceutical Co. Gavin Giovannoni has received speaker honoraria and consulting fees from AbbVie, Actelion, Almirall, Atara Bio, Bayer Schering Pharma, Biogen Idec, Five Prime, GlaxoSmithKline, GW Pharmaceuticals, Ironwood, Merck \& Co., Merck KGaA, Novartis, Pfizer Inc., Protein Discovery Laboratories, Sanofi-Genzyme, Teva Pharmaceutical Industries Ltd, UCB and Vertex Pharmaceuticals. Samuel F. Hunter reports having served as a consultant for AbbVie, Bayer, Genentech/Roche and Sanofi-Genzyme; participation in clinical research trials for Actelion, Adamas, Genentech/Roche, Osmotica and Teva; receipt of research grant support from Sanofi-Genzyme; serving on speakers' bureaux for Mallinckrodt, Novartis, Sanofi-Genzyme and Teva.

Funding Medical writing assistance was provided by Dr Ian M. Williams of Oxford PharmaGenesis, Oxford, UK, and supported by Novartis Pharmaceuticals Corporation, East Hanover, NJ, USA. Openaccess publication was funded by Novartis Pharmaceuticals Corporation.

Ethics approval Not applicable.

Consent to participate Not applicable.

Consent for publication Not applicable.

Availability of data and material Data sharing is not applicable to this article as no datasets were generated or analysed for this review.

Author contributions All authors contributed equally to the conception of this work, the interpretation of the literature and the drafting of the manuscript. All authors critically revised the review for intellectual content and approved the final manuscript for publication.

Open Access This article is licensed under a Creative Commons Attribution-NonCommercial 4.0 International License, which permits any non-commercial use, sharing, adaptation, distribution and reproduction in any medium or format, as long as you give appropriate credit to the original author(s) and the source, provide a link to the Creative Commons licence, and indicate if changes were made. The images or other third party material in this article are included in the article's Creative Commons licence, unless indicated otherwise in a credit line to the material. If material is not included in the article's Creative Commons licence and your intended use is not permitted by statutory regulation or exceeds the permitted use, you will need to obtain permission directly from the copyright holder. To view a copy of this licence, visit http://creativecommons.org/licenses/by-nc/4.0/.

\section{References}

1. Kihara Y, Maceyka M, Spiegel S, Chun J. Lysophospholipid receptor nomenclature review: IUPHAR review 8 . Br J Pharmacol. 2014;171(15):3575-94. https://doi.org/10.1111/bph.12678. 
2. Mutoh T, Rivera R, Chun J. Insights into the pharmacological relevance of lysophospholipid receptors. Br J Pharmacol. 2012;165(4):829-44. https://doi.org/10.111 1/j.1476-5381.2011.01622.x.

3. Kihara Y, Misuno H, Chun J. Lysophospholipid receptors in drug discovery. Exp Cell Res. 2015;333(2):171-7. https://doi. org/10.1016/j.yexcr.2014.11.020.

4. Kunkel GT, Maceyka M, Milstien S, Spiegel S. Targeting the sphingosine-1-phosphate axis in cancer, inflammation and beyond. Nat Rev Drug Discov. 2013;12(9):688-702. https://doi. org/10.1038/nrd4099.

5. Novartis Pharmaceuticals Corporation. Mayzent ${ }^{\circledR}$ — prescribing information (2019). https://www.pharma.us.novartis.com/sites /www.pharma.us.novartis.com/files/mayzent.pdf. Accessed 19 Sept 2019.

6. European Medicines Agency. Mayzent: EPAR—product information (2020). https://www.ema.europa.eu/en/documents/productinformation/mayzent-epar-product-information_en.pdf. Accessed 13 Feb 2020.

7. Australian Government: Department of Health Therapeutic Goods Administration. Australian prescription medicine decision summaries-Mayzent. https://www.tga.gov.au/apm-summa ry/mayzent (2019). Accessed 13 Feb 2020.

8. Novartis Pharma KK: Novartis receives simultaneous approval for five new products from Japanese Ministry of Health, Labour and Welfare, offering Japanese patients a broad range of novel treatment options. https://www.novartis.com/news/media-relea ses/novartis-receives-simultaneous-approval-five-new-produ cts-from-japanese-ministry-health-labour-and-welfare-offeringjapanese-patients-broad-range-novel (2020). Accessed 29 July 2020.

9. Kappos L, Bar-Or A, Cree BAC, Fox RJ, Giovannoni G, Gold $\mathrm{R}$, et al. Siponimod versus placebo in secondary progressive multiple sclerosis (EXPAND): a double-blind, randomised, phase 3 study. Lancet. 2018;391(10127):1263-73. https://doi. org/10.1016/S0140-6736(18)30475-6.

10. Bristol Myers Squibb Pharmaceutical Corporation: Zeposia ${ }^{\circledR}$ prescribing information. https://www.accessdata.fda.gov/drugs atfda_docs/label/2020/209899s0001bl.pdf (2020). Accessed 7 Apr 2020

11. Comi G, Kappos L, Selmaj KW, Bar-Or A, Arnold DL, Steinman L, et al. Safety and efficacy of ozanimod versus interferon beta-1a in relapsing multiple sclerosis (SUNBEAM): a multicentre, randomised, minimum 12-month, phase 3 trial. Lancet Neurol. 2019;18(11):1009-20. https://doi.org/10.1016/S1474 -4422(19)30239-X.

12. Cohen JA, Comi G, Selmaj KW, Bar-Or A, Arnold DL, Steinman L, et al. Safety and efficacy of ozanimod versus interferon beta-1a in relapsing multiple sclerosis (RADIANCE): a multicentre, randomised, 24-month, phase 3 trial. Lancet Neurol. 2019;18(11):1021-33. https://doi.org/10.1016/S1474 $-4422(19) 30238-8$

13. European Medicines Agency: Zeposia-authorisation details. https://www.ema.europa.eu/en/medicines/human/EPAR/zepos ia\#authorisation-details-section (2020). Accessed 22 July 2020.

14. Gardell SE, Dubin AE, Chun J. Emerging medicinal roles for lysophospholipid signaling. Trends Mol Med. 2006;12(2):65-75. https://doi.org/10.1016/j.molmed.2005.12.001.

15. Chun J, Kihara Y, Jonnalagadda D, Blaho VA. Fingolimod: lessons learned and new opportunities for treating multiple sclerosis and other disorders. Annu Rev Pharmacol Toxicol. 2019;59:14970. https://doi.org/10.1146/annurev-pharmtox-010818-021358.

16. Ishii I, Fukushima N, Ye X, Chun J. Lysophospholipid receptors: signaling and biology. Annu Rev Biochem. 2004;73:321-54. https://doi.org/10.1146/annurev.biochem.73.011303.073731.
17. Choi JW, Herr DR, Noguchi K, Yung YC, Lee CW, Mutoh T, et al. LPA receptors: subtypes and biological actions. Annu Rev Pharmacol Toxicol. 2010;50:157-86. https://doi.org/10.1146/ annurev.pharmtox.010909.105753.

18. Fukushima N, Ishii I, Contos JJ, Weiner JA, Chun J. Lysophospholipid receptors. Annu Rev Pharmacol Toxicol. 2001;41:50734. https://doi.org/10.1146/annurev.pharmtox.41.1.507.

19. Spiegel S, Milstien S. Sphingosine-1-phosphate: an enigmatic signalling lipid. Nat Rev Mol Cell Biol. 2003;4(5):397-407. https ://doi.org/10.1038/nrm1103.

20. Chun J, Weiner JA, Fukushima N, Contos JJ, Zhang G, Kimura Y, et al. Neurobiology of receptor-mediated lysophospholipid signaling. From the first lysophospholipid receptor to roles in nervous system function and development. Ann N Y Acad Sci. 2000;905:110-7. https://doi.org/10.1111/j.1749-6632.2000. tb06543.x.

21. Soliven B, Miron V, Chun J. The neurobiology of sphingosine 1-phosphate signaling and sphingosine 1-phosphate receptor modulators. Neurology. 2011;76(8 Suppl 3):S9-14. https://doi. org/10.1212/WNL.0b013e31820d9507.

22. Blaho VA, Hla T. Regulation of mammalian physiology, development, and disease by the sphingosine 1-phosphate and lysophosphatidic acid receptors. Chem Rev. 2011;111(10):6299-320. https://doi.org/10.1021/cr200273u.

23. Meacci E, Garcia-Gil M. S1P/S1P receptor signaling in neuromuscolar disorders. Int J Mol Sci. 2019;20(24):6364. https://doi. org/10.3390/ijms20246364.

24. Choi JW, Lee CW, Chun J. Biological roles of lysophospholipid receptors revealed by genetic null mice: an update. Biochim Biophys Acta. 2008;1781(9):531-9. https://doi.org/10.1016/j.bbali p.2008.03.004

25. Christensen PM, Bosteen MH, Hajny S, Nielsen LB, Christoffersen C. Apolipoprotein M mediates sphingosine-1-phosphate efflux from erythrocytes. Sci Rep. 2017;7(1):14983. https://doi. org/10.1038/s41598-017-15043-y.

26. Cantalupo A, Di Lorenzo A. S1P signaling and de novo biosynthesis in blood pressure homeostasis. J Pharmacol Exp Ther. 2016;358(2):359-70. https://doi.org/10.1124/jpet.116.233205.

27. Nofer JR, van der Giet M, Tolle M, Wolinska I, von Wnuck Lipinski K, Baba HA, et al. HDL induces NO-dependent vasorelaxation via the lysophospholipid receptor S1P3. J Clin Invest. 2004;113(4):569-81. https://doi.org/10.1172/JCI18004.

28. Hajny S, Christoffersen C. A novel perspective on the ApoM-S1P axis, highlighting the metabolism of ApoM and its role in liver fibrosis and neuroinflammation. Int J Mol Sci. 2017;18(8):1636. https://doi.org/10.3390/ijms18081636.

29. Vogt D, Stark H. Therapeutic strategies and pharmacological tools influencing S1P signaling and metabolism. Med Res Rev. 2017;37(1):3-51. https://doi.org/10.1002/med.21402.

30. Urbano M, Guerrero M, Rosen H, Roberts E. Modulators of the sphingosine 1-phosphate receptor 1. Bioorg Med Chem Lett. 2013;23(23):6377-89. https://doi.org/10.1016/j. bmcl.2013.09.058.

31. Hanson MA, Roth CB, Jo E, Griffith MT, Scott FL, Reinhart $\mathrm{G}$, et al. Crystal structure of a lipid $\mathrm{G}$ protein-coupled receptor. Science. 2012;335(6070):851-5. https://doi.org/10.1126/scien ce. 1215904.

32. Chrencik JE, Roth CB, Terakado M, Kurata H, Omi R, Kihara $\mathrm{Y}$, et al. Crystal structure of antagonist bound human lysophosphatidic acid receptor 1. Cell. 2015;161(7):1633-43. https://doi. org/10.1016/j.cell.2015.06.002.

33. Blaho VA, Chun J. 'Crystal' clear? Lysophospholipid receptor structure insights and controversies. Trends Pharmacol Sci. 2018;39(11):953-66. https://doi.org/10.1016/j.tips.2018.08.006.

34. Brinkmann V, Davis MD, Heise CE, Albert R, Cottens S, Hof $\mathrm{R}$, et al. The immune modulator FTY720 targets sphingosine 
1-phosphate receptors. J Biol Chem. 2002;277(24):21453-7. https://doi.org/10.1074/jbc.C200176200.

35. Sugahara K, Maeda Y, Shimano K, Mogami A, Kataoka H, Ogawa K, et al. Amiselimod, a novel sphingosine 1-phosphate receptor-1 modulator, has potent therapeutic efficacy for autoimmune diseases, with low bradycardia risk. Br J Pharmacol. 2017;174(1):15-27. https://doi.org/10.1111/bph.13641.

36. Pan S, Gray NS, Gao W, Mi Y, Fan Y, Wang X, et al. Discovery of BAF312 (siponimod), a potent and selective S1P receptor modulator. ACS Med Chem Lett. 2013;4(3):333-7. https://doi. org/10.1021/ml300396r.

37. Kovarik JM, Schmouder R, Barilla D, Wang Y, Kraus G. Single-dose FTY720 pharmacokinetics, food effect, and pharmacological responses in healthy subjects. Br J Clin Pharmacol. 2004;57(5):586-91. https://doi.org/10.111 1/j.1365-2125.2003.02065.x.

38. Sanna MG, Vincent KP, Repetto E, Nguyen N, Brown SJ, Abgaryan L, et al. Bitopic sphingosine 1-phosphate receptor 3 (S1P3) antagonist rescue from complete heart block: pharmacological and genetic evidence for direct S1P3 regulation of mouse cardiac conduction. Mol Pharmacol. 2016;89(1):176-86. https://doi. org $/ 10.1124 / \mathrm{mol} .115 .100222$

39. Gergely P, Nuesslein-Hildesheim B, Guerini D, Brinkmann V, Traebert M, Bruns C, et al. The selective sphingosine 1-phosphate receptor modulator BAF312 redirects lymphocyte distribution and has species-specific effects on heart rate. $\mathrm{Br}$ J Pharmacol. 2012;167(5):1035-47. https://doi.org/10.111 1/j.1476-5381.2012.02061.x.

40. Krosser S, Wolna P, Fischer TZ, Boschert U, Stoltz R, Zhou $\mathrm{M}$, et al. Effect of ceralifimod (ONO-4641) on lymphocytes and cardiac function: randomized, double-blind, placebo-controlled trial with an open-label fingolimod arm. J Clin Pharmacol. 2015;55(9):1051-60. https://doi.org/10.1002/jcph.513.

41. Fischer I, Alliod C, Martinier N, Newcombe J, Brana C, Pouly $\mathrm{S}$. Sphingosine kinase 1 and sphingosine 1-phosphate receptor 3 are functionally upregulated on astrocytes under pro-inflammatory conditions. PLoS One. 2011;6(8):e23905. https://doi. org/10.1371/journal.pone.0023905.

42. Dusaban SS, Chun J, Rosen H, Purcell NH, Brown JH. Sphingosine 1-phosphate receptor 3 and RhoA signaling mediate inflammatory gene expression in astrocytes. J Neuroinflamm. 2017;14(1):111. https://doi.org/10.1186/s12974-017-0882-x.

43. Chakkour M, Kreydiyyeh S. FTY720P upregulates the $\mathrm{Na}^{+} /$ $\mathrm{K}^{+}$ATPase in HepG2 cells by activating S1PR3 and inducing PGE2 release. Cell Physiol Biochem. 2019;53(3):518-31. https ://doi.org/10.33594/000000155.

44. Jongsma M, van Unen J, van Loenen PB, Michel MC, Peters SL, Alewijnse AE. Different response patterns of several ligands at the sphingosine-1-phosphate receptor subtype $3(\mathrm{~S} 1 \mathrm{P}(3))$. Br J Pharmacol. 2009;156(8):1305-11. https://doi.org/10.111 1/j.1476-5381.2009.00134.x.

45. Riddy DM, Stamp C, Sykes DA, Charlton SJ, Dowling MR. Reassessment of the pharmacology of sphingosine-1-phosphate S1P3 receptor ligands using the DiscoveRx PathHunter and $\mathrm{Ca}^{2+}$ release functional assays. Br J Pharmacol. 2012;167(4):868-80. https://doi.org/10.1111/j.1476-5381.2012.02032.x.

46. Huwiler A, Zangemeister-Wittke U. The sphingosine 1-phosphate receptor modulator fingolimod as a therapeutic agent: recent findings and new perspectives. Pharmacol Ther. 2018;185:34-49. https://doi.org/10.1016/j.pharmthera.2017.11.001.

47. Masse K, Kyuno J, Bhamra S, Jones EA. The lysophosphatidic acid (LPA) and sphingosine-1-phosphate (S1P) receptor gene families: cloning and comparative expression analysis in Xenopus laevis. Int J Dev Biol. 2010;54(8-9):1361-74. https://doi. org/10.1387/ijdb.103068km.
48. Matloubian M, Lo CG, Cinamon G, Lesneski MJ, Xu Y, Brinkmann $\mathrm{V}$, et al. Lymphocyte egress from thymus and peripheral lymphoid organs is dependent on S1P receptor 1. Nature. 2004;427(6972):355-60. https://doi.org/10.1038/nature02284.

49. Groves A, Kihara Y, Chun J. Fingolimod: direct CNS effects of sphingosine 1-phosphate (S1P) receptor modulation and implications in multiple sclerosis therapy. J Neurol Sci. 2013;328(12):9-18. https://doi.org/10.1016/j.jns.2013.02.011.

50. Prager B, Spampinato SF, Ransohoff RM. Sphingosine 1-phosphate signaling at the blood-brain barrier. Trends Mol Med. 2015;21(6):354-63. https://doi.org/10.1016/j.molme d.2015.03.006.

51. Takabe K, Paugh SW, Milstien S, Spiegel S. "Inside-out" signaling of sphingosine-1-phosphate: therapeutic targets. Pharmacol Rev. 2008;60(2):181-95. https://doi.org/10.1124/pr.107.07113.

52. Bigaud M, Guerini D, Billich A, Bassilana F, Brinkmann V. Second generation S1P pathway modulators: research strategies and clinical developments. Biochim Biophys Acta. 2014;1841(5):745-58. https://doi.org/10.1016/j.bbali p.2013.11.001.

53. Schulze T, Golfier S, Tabeling C, Rabel K, Graler MH, Witzenrath M, et al. Sphingosine-1-phospate receptor 4 (S1P(4)) deficiency profoundly affects dendritic cell function and TH17-cell differentiation in a murine model. FASEB J. 2011;25(11):4024 36. https://doi.org/10.1096/fj.10-179028.

54. Brinkmann V. Sphingosine 1-phosphate receptors in health and disease: mechanistic insights from gene deletion studies and reverse pharmacology. Pharmacol Ther. 2007;115(1):84-105. https://doi.org/10.1016/j.pharmthera.2007.04.006.

55. Comi G, Hartung HP, Bakshi R, Williams IM, Wiendl H. Benefit-risk profile of sphingosine-1-phosphate receptor modulators in relapsing and secondary progressive multiple sclerosis. Drugs. 2017;77(16):1755-68. https://doi.org/10.1007/s4026 5-017-0814-1.

56. Jenne CN, Enders A, Rivera R, Watson SR, Bankovich AJ, Pereira JP, et al. T-bet-dependent S1P5 expression in NK cells promotes egress from lymph nodes and bone marrow. J Exp Med. 2009;206(11):2469-81. https://doi.org/10.1084/jem.20090525.

57. Windh RT, Lee MJ, Hla T, An S, Barr AJ, Manning DR. Differential coupling of the sphingosine 1-phosphate receptors Edg-1, Edg-3, and H218/Edg-5 to the G(i), G(q), and G(12) families of heterotrimeric G proteins. J Biol Chem. 1999;274(39):27351-8. https://doi.org/10.1074/jbc.274.39.27351.

58. Young N, Van Brocklyn JR. Signal transduction of sphingosine1-phosphate $\mathrm{G}$ protein-coupled receptors. ScientificWorldJournal. 2006;6:946-66. https://doi.org/10.1100/tsw.2006.182.

59. Gajofatto A. Spotlight on siponimod and its potential in the treatment of secondary progressive multiple sclerosis: the evidence to date. Drug Des Devel Ther. 2017;11:3153-7. https://doi. org/10.2147/DDDT.S122249.

60. Scott FL, Clemons B, Brooks J, Brahmachary E, Powell R, Dedman H, et al. Ozanimod (RPC1063) is a potent sphingosine1-phosphate receptor-1 (S1P1) and receptor-5 (S1P5) agonist with autoimmune disease-modifying activity. Br J Pharmacol. 2016;173(11):1778-92. https://doi.org/10.1111/bph.13476.

61. Brossard P, Derendorf H, Xu J, Maatouk H, Halabi A, Dingemanse J. Pharmacokinetics and pharmacodynamics of ponesimod, a selective S1P1 receptor modulator, in the first-in-human study. Br J Clin Pharmacol. 2013;76(6):888-96. https://doi. org/10.1111/bcp.12129.

62. Piali L, Froidevaux S, Hess P, Nayler O, Bolli MH, Schlosser E, et al. The selective sphingosine 1-phosphate receptor 1 agonist ponesimod protects against lymphocyte-mediated tissue inflammation. J Pharmacol Exp Ther. 2011;337(2):547-56. https://doi. org/10.1124/jpet.110.176487. 
63. Tran JQ, Hartung JP, Peach RJ, Boehm MF, Rosen H, Smith $\mathrm{H}$, et al. Results from the first-in-human study with ozanimod, a novel, selective sphingosine-1-phosphate receptor modulator. J Clin Pharmacol. 2017;57(8):988-96. https://doi.org/10.1002/ jcph.887.

64. Tran JQ, Zhang P, Surapaneni S, Selkirk J, Yan G, Palmisano M. Absorption, metabolism, and excretion, in vitro pharmacology, and clinical pharmacokinetics of ozanimod, a novel sphingosine 1-phosphate receptor agonist. Mult Scler. 2019;25(S2):524 (P993).

65. Tran JQ, Hartung JP, Olson AD, Mendzelevski B, Timony GA, Boehm MF, et al. Cardiac safety of ozanimod, a novel sphingosine-1-phosphate receptor modulator: results of a thorough QT/ QTc study. Clin Pharmacol Drug Dev. 2018;7(3):263-76. https ://doi.org/10.1002/cpdd.383.

66. Rasche L, Paul F. Ozanimod for the treatment of relapsing remitting multiple sclerosis. Expert Opin Pharmacother. 2018;19(18):2073-86. https://doi.org/10.1080/14656 566.2018.1540592.

67. Olsson T, Boster A, Fernandez O, Freedman MS, Pozzilli C, Bach D, et al. Oral ponesimod in relapsing-remitting multiple sclerosis: a randomised phase II trial. J Neurol Neurosurg Psychiatry. 2014;85(11):1198-208. https://doi.org/10.1136/jnnp2013-307282.

68. Xu J, Gray F, Henderson A, Hicks K, Yang J, Thompson P, et al. Safety, pharmacokinetics, pharmacodynamics, and bioavailability of GSK2018682, a sphingosine-1-phosphate receptor modulator, in healthy volunteers. Clin Pharmacol Drug Dev. 2014;3(3):170-8. https://doi.org/10.1002/cpdd.98.

69. Brinkmann V. FTY720 (fingolimod) in multiple sclerosis: therapeutic effects in the immune and the central nervous system. Br J Pharmacol. 2009;158(5):1173-82. https://doi.org/10.111 1/j.1476-5381.2009.00451.x.

70. Chun J, Hartung HP. Mechanism of action of oral fingolimod (FTY720) in multiple sclerosis. Clin Neuropharmacol. 2010;33(2):91-101. https://doi.org/10.1097/WNF.0b013e3181 cbf825.

71. Choi JW, Gardell SE, Herr DR, Rivera R, Lee CW, Noguchi $\mathrm{K}$, et al. FTY720 (fingolimod) efficacy in an animal model of multiple sclerosis requires astrocyte sphingosine 1-phosphate receptor 1 (S1P1) modulation. Proc Natl Acad Sci USA. 2011;108(2):751-6. https://doi.org/10.1073/pnas.1014154108.

72. Kappos L, Radue EW, O'Connor P, Polman C, Hohlfeld R, Calabresi $\mathrm{P}$, et al. A placebo-controlled trial of oral fingolimod in relapsing multiple sclerosis. N Engl J Med. 2010;362(5):387401. https://doi.org/10.1056/NEJMoa0909494.

73. Calabresi PA, Radue EW, Goodin D, Jeffery D, Rammohan KW, Reder AT, et al. Safety and efficacy of fingolimod in patients with relapsing-remitting multiple sclerosis (FREEDOMS II): a double-blind, randomised, placebo-controlled, phase 3 trial. Lancet Neurol. 2014;13(6):545-56. https://doi.org/10.1016/S1474 -4422(14)70049-3.

74. Cohen JA, Barkhof F, Comi G, Hartung HP, Khatri BO, Montalban X, et al. Oral fingolimod or intramuscular interferon for relapsing multiple sclerosis. N Engl J Med. 2010;362(5):402-15. https://doi.org/10.1056/NEJMoa0907839.

75. Sastre-Garriga J, Tur C, Pareto D, Vidal-Jordana A, Auger C, Rio J, et al. Brain atrophy in natalizumab-treated patients: a 3-year follow-up. Mult Scler. 2015;21(6):749-56. https://doi. org/10.1177/1352458514556300.

76. Camm J, Hla T, Bakshi R, Brinkmann V. Cardiac and vascular effects of fingolimod: mechanistic basis and clinical implications. Am Heart J. 2014;168(5):632-44. https://doi.org/10.1016/j. ahj.2014.06.028.

77. O'Sullivan C, Schubart A, Mir AK, Dev KK. The dual S1PR1/ S1PR5 drug BAF312 (Siponimod) attenuates demyelination in organotypic slice cultures. J Neuroinflamm. 2016;13:31. https:// doi.org/10.1186/s12974-016-0494-x.

78. Selmaj K, Li DK, Hartung HP, Hemmer B, Kappos L, Freedman MS, et al. Siponimod for patients with relapsing-remitting multiple sclerosis (BOLD): an adaptive, dose-ranging, randomised, phase 2 study. Lancet Neurol. 2013;12(8):756-67. https://doi. org/10.1016/S1474-4422(13)70102-9.

79. Jurcevic S, Juif PE, Hamid C, Greenlaw R, D'Ambrosio D, Dingemanse J. Effects of multiple-dose ponesimod, a selective S1P1 receptor modulator, on lymphocyte subsets in healthy humans. Drug Des Devel Ther. 2017;11:123-31. https://doi.org/10.2147/ DDDT.S120399.

80. Bigaud M, Tisserand S, Fuchs-Loesle P, Guerini D. The S1P receptor is not down-modulated in response to selective agonists. Mult Scler. 2018;24(S2):913 (EPoster 1617).

81. Hammarlund-Udenaes M, Friden M, Syvanen S, Gupta A. On the rate and extent of drug delivery to the brain. Pharm Res. 2008;25(8):1737-50. https://doi.org/10.1007/s1109 5-007-9502-2.

82. Tavares A, Barret O, Alagille D, Morley T, Papin C, Maguire $\mathrm{RP}$, et al. Brain distribution of MS565, an imaging analogue of siponimod (BAF312), in non-human primates. Neurology. 2014;82(P1):168.

83. Tamagnan G, Tavares A, Barret O, Alagille D, Seibyl J, Marek $\mathrm{K}$, et al. Brain distribution of BZM055, an analog of fingolimod (FTY720), in human. Mult Scler. 2012;18(10 S4):Abstract P839.

84. Bigaud M, Perdoux J, Ramseier P, Tisserand S, Urban B, Beerli C. Pharmacokinetic/pharmacodynamic characterization of siponimod (BAF312) in blood versus brain in experimental autoimmune encephalomyelitis mice (P2.2-066). Neurology. 2019;92 (15 Supplement):2.2-066P.

85. Bigaud M, Tisserand S, Ramseier P, Lang M, Perdoux J, Urban $\mathrm{B}$, et al. Differentiated pharmacokinetic/pharmacodynamic (PK/ PD) profiles for siponimod (BAF312) versus fingolimod. Mult Scler. 2019;25(S2):300-1 (Poster 622).

86. Kim HJ, Miron VE, Dukala D, Proia RL, Ludwin SK, Traka $M$, et al. Neurobiological effects of sphingosine 1-phosphate receptor modulation in the cuprizone model. FASEB J. 2011;25(5):1509-18. https://doi.org/10.1096/fj.10-173203.

87. Sheridan GK, Dev KK. S1P1 receptor subtype inhibits demyelination and regulates chemokine release in cerebellar slice cultures. Glia. 2012;60(3):382-92. https://doi.org/10.1002/ glia.22272.

88. O'Sullivan S, Dev KK. Sphingosine-1-phosphate receptor therapies: advances in clinical trials for CNS-related diseases. Neuropharmacology. 2017;113(Pt B):597-607. https://doi.org/10.1016/j. neuropharm.2016.11.006.

89. Pyne NJ, Pyne S. Sphingosine 1-phosphate receptor 1 signaling in mammalian cells. Molecules. 2017;22(3):344. https://doi. org/10.3390/molecules22030344.

90. Mehling M, Brinkmann V, Antel J, Bar-Or A, Goebels N, Vedrine C, et al. FTY720 therapy exerts differential effects on T cell subsets in multiple sclerosis. Neurology. 2008;71(16):1261-7. https ://doi.org/10.1212/01.wnl.0000327609.57688.ea.

91. Wu Q, Mills EA, Wang Q, Dowling CA, Fisher C, Kirch B, et al. Siponimod enriches regulatory $\mathrm{T}$ and $\mathrm{B}$ lymphocytes in secondary progressive multiple sclerosis. JCI Insight. 2020;5(3):e134251. https://doi.org/10.1172/jci.insight.134251.

92. Dehmel T, Heininger M, Pleiser S, Seibert S, Putzki N, Bernd K, et al. Cellular composition of peripheral blood mononuclear cells during 4 years long-term treatment with fingolimod. Neurology. 2017;88(Suppl.16):P5.364.

93. Moreno-Torres I, Gonzalez-Garcia C, Marconi M, GarciaGrande A, Rodriguez-Esparragoza L, Elvira V, et al. Immunophenotype and transcriptome profile of patients with multiple 
sclerosis treated with fingolimod: setting up a model for prediction of response in a 2-year translational study. Front Immunol. 2018;9:1693. https://doi.org/10.3389/fimmu.2018.01693.

94. Novartis Pharmaceuticals Corporation: Data on file (August 2020). GILENYA exposure. May 2020 cutoff (2020). Accessed 2 Sept 2020.

95. Arvin AM, Wolinsky JS, Kappos L, Morris MI, Reder AT, Tornatore $\mathrm{C}$, et al. Varicella-zoster virus infections in patients treated with fingolimod: risk assessment and consensus recommendations for management. JAMA Neurol. 2015;72(1):31-9. https:// doi.org/10.1001/jamaneurol.2014.3065.

96. Novartis Pharmaceuticals Corporation: Gilenya ${ }^{\circledR}$ — prescribing information. https://www.pharma.us.novartis.com/sites/www. pharma.us.novartis.com/files/gilenya.pdf (2017). Accessed 11 Apr 2018.

97. Centers for Disease Control and Prevention: Varicella vaccine recommendations. 2019. https://www.cdc.gov/vaccines/vpd/varic ella/hcp/recommendations.html. Accessed 22 July 2020.

98. Ufer M, Shakeri-Nejad K, Gardin A, Su Z, Paule I, Marbury TC, et al. Impact of siponimod on vaccination response in a randomized, placebo-controlled study. Neurol Neuroimmunol Neuroinflamm. 2017;4(6):e398. https://doi.org/10.1212/NXI.00000 00000000398.

99. Hunter SF, Bowen JD, Reder AT. The direct effects of fingolimod in the central nervous system: implications for relapsing multiple sclerosis. CNS Drugs. 2016;30(2):135-47. https://doi. org/10.1007/s40263-015-0297-0.

100. Grassi S, Mauri L, Prioni S, Cabitta L, Sonnino S, Prinetti A, et al. Sphingosine 1-phosphate receptors and metabolic enzymes as druggable targets for brain diseases. Front Pharmacol. 2019;10:807. https://doi.org/10.3389/fphar.2019.00807.

101. Zhang Y, Li X, Ciric B, Ma CG, Gran B, Rostami A, et al. Effect of fingolimod on neural stem cells: a novel mechanism and broadened application for neural repair. Mol Ther. 2017;25(2):401-15. https://doi.org/10.1016/j.ymthe.2016.12.008.

102. Palumbo S, Pellegrini S. Experimental in vivo models of multiple sclerosis: state of the art [Internet]. In: Zagon IS, McLaughlin PJ, editors. Multiple sclerosis: perspectives in treatment and pathogenesis. Brisbane (AU): Codon Publications; 2017.

103. Groves A, Kihara Y, Jonnalagadda D, Rivera R, Kennedy G, Mayford M, et al. A functionally defined in vivo astrocyte population identified by c-Fos activation in a mouse model of multiple sclerosis modulated by S1P signaling: immediate-early astrocytes (ieAstrocytes). eNeuro. 2018;5(5):ENEURO.0239-18.2018. https ://doi.org/10.1523/ENEURO.0239-18.2018.

104. Rothhammer V, Kenison JE, Tjon E, Takenaka MC, de Lima KA, Borucki DM, et al. Sphingosine 1-phosphate receptor modulation suppresses pathogenic astrocyte activation and chronic progressive CNS inflammation. Proc Natl Acad Sci USA. 2017;114(8):2012-17. https://doi.org/10.1073/pnas.1615413114.

105. Wu C, Leong SY, Moore CS, Cui QL, Gris P, Bernier LP, et al. Dual effects of daily FTY720 on human astrocytes in vitro: relevance for neuroinflammation. J Neuroinflamm. 2013;10:41. https://doi.org/10.1186/1742-2094-10-41.

106. Gentile A, Musella A, Bullitta S, Fresegna D, De Vito F, Fantozzi R, et al. Siponimod (BAF312) prevents synaptic neurodegeneration in experimental multiple sclerosis. J Neuroinflamm. 2016;13(1):207. https://doi.org/10.1186/s12974-016-0686-4.

107. Ward LA, Lee DS, Sharma A, Wang A, Naouar I, Ma XI, et al. Siponimod therapy implicates Th17 cells in a preclinical model of subpial cortical injury. JCI Insight. 2020;5(1):e132522. https ://doi.org/10.1172/jci.insight.132522.

108. Seabrook TJ, Smith P, Schweitzer A, Wallström E, NuessleinHildesheim B. Efficacy of the selective S1P 1/5 modulator, BAF312 in established experimental autoimmune encephalomyelitis and redistribution of S1P1 and S1P5 in the inflamed human CNS tissue. Mult Scler. 2010;16:S301 [Abstract P858].

109. Cuzzocrea S, Doyle T, Campolo M, Paterniti I, Esposito E, Farr SA, et al. Sphingosine 1-phosphate receptor subtype 1 as a therapeutic target for brain trauma. J Neurotrauma. 2018;35(13):145266. https://doi.org/10.1089/neu.2017.5391.

110. Mandolesi G, Gentile A, Musella A, Fresegna D, De Vito F, Bullitta S, et al. Synaptopathy connects inflammation and neurodegeneration in multiple sclerosis. Nat Rev Neurol. 2015;11(12):711-24. https://doi.org/10.1038/nrneurol.2015.222.

111. Hundehege P, Cerina M, Eichler S, Thomas C, Herrmann AM, Gobel K, et al. The next-generation sphingosine-1 receptor modulator BAF312 (siponimod) improves cortical network functionality in focal autoimmune encephalomyelitis. Neural Regen Res. 2019;14(11):1950-60. https://doi.org/10.4103/1673-5374.25962 2.

112. Musella A, Gentile A, Guadalupi L, Rizzo FR, De Vito F, Fresegna D, et al. Central modulation of selective sphingosine1-phosphate receptor 1 ameliorates experimental multiple sclerosis. Cells. 2020;9(5):1290. https://doi.org/10.3390/cells90512 90.

113. Dong YF, Guo RB, Ji J, Cao LL, Zhang L, Chen ZZ, et al. S1PR3 is essential for phosphorylated fingolimod to protect astrocytes against oxygen-glucose deprivation-induced neuroinflammation via inhibiting TLR2/4-NFkappaB signalling. J Cell Mol Med. 2018;22(6):3159-66. https://doi.org/10.1111/jcmm.13596.

114. Jackson SJ, Giovannoni G, Baker D. Fingolimod modulates microglial activation to augment markers of remyelination. J Neuroinflamm. 2011;8:76. https://doi.org/10.1186/1742-2094-8-76.

115. Tiwari-Woodruff S, Yamate-Morgan H, Sekyi M, Lauderdale K, Hasselmann J, Schubart A. The sphingosine 1-phosphate (s1p) receptor modulator, siponimod decreases oligodendrocyte cell death and axon demyelination in a mouse model of multiple sclerosis. Neurology. 2016;86(16 SUPPL):P5.325.

116. Mannioui A, Vauzanges Q, Fini JB, Henriet E, Sekizar S, Azoyan L, et al. The Xenopus tadpole: an in vivo model to screen drugs favoring remyelination. Mult Scler. 2018;24(11):1421-32. https ://doi.org/10.1177/1352458517721355.

117. Miron VE, Ludwin SK, Darlington PJ, Jarjour AA, Soliven B, Kennedy TE, et al. Fingolimod (FTY720) enhances remyelination following demyelination of organotypic cerebellar slices. Am J Pathol. 2010;176(6):2682-94. https://doi.org/10.2353/ajpat h.2010.091234.

118. Yazdi A, Baharvand H, Javan M. Enhanced remyelination following lysolecithin-induced demyelination in mice under treatment with fingolimod (FTY720). Neuroscience. 2015;311:34-44. https ://doi.org/10.1016/j.neuroscience.2015.10.013.

119. Nagai J, Uchida H, Matsushita Y, Yano R, Ueda M, Niwa M, et al. Autotaxin and lysophosphatidic acid1 receptor-mediated demyelination of dorsal root fibers by sciatic nerve injury and intrathecal lysophosphatidylcholine. Mol Pain. 2010;6:78. https ://doi.org/10.1186/1744-8069-6-78.

120. Anliker B, Choi JW, Lin ME, Gardell SE, Rivera RR, Kennedy $\mathrm{G}$, et al. Lysophosphatidic acid (LPA) and its receptor, LPA1, influence embryonic schwann cell migration, myelination, and cell-to-axon segregation. Glia. 2013;61(12):2009-22. https://doi. org/10.1002/glia.22572.

121. Miron VE, Jung CG, Kim HJ, Kennedy TE, Soliven B, Antel JP. FTY720 modulates human oligodendrocyte progenitor process extension and survival. Ann Neurol. 2008;63(1):61-71. https:// doi.org/10.1002/ana.21227.

122. Smith PA, Schmid C, Zurbruegg S, Jivkov M, Doelemeyer A, Theil D, et al. Fingolimod inhibits brain atrophy and promotes brain-derived neurotrophic factor in an animal model of 
multiple sclerosis. J Neuroimmunol. 2018;318:103-13. https:// doi.org/10.1016/j.jneuroim.2018.02.016.

123. Deogracias R, Schubart A, Barde Y-A. Siponimod increases brain-derived neurotrophic factor (BDNF) levels in cortical neuronal cultures and naïve healthy mice. Mult Scler. 2018;24(S2):894-5 (EPoster 1582).

124. Legangneux E, Gardin A, Johns D. Dose titration of BAF312 attenuates the initial heart rate reducing effect in healthy subjects. Br J Clin Pharmacol. 2013;75(3):831-41. https://doi.org/10.111 1/j.1365-2125.2012.04400.x.

125. DiMarco JP, O'Connor P, Cohen JA, Reder AT, Zhang-Auberson L, Tang D, et al. First-dose effects of fingolimod: pooled safety data from three phase 3 studies. Mult Scler Relat Disord. 2014;3(5):629-38. https://doi.org/10.1016/j.msard.2014.05.005.

126. Kappos L, Cohen J, Collins W, de Vera A, Zhang-Auberson L, Ritter S, et al. Fingolimod in relapsing multiple sclerosis: an integrated analysis of safety findings. Mult Scler Relat Disord. 2014;3(4):494-504. https://doi.org/10.1016/j.msard .2014.03.002

127. Noseworthy JH, Lucchinetti C, Rodriguez M, Weinshenker BG. Multiple sclerosis. N Engl J Med. 2000;343(13):938-52. https ://doi.org/10.1056/NEJM200009283431307.

128. Compston A, Coles A. Multiple sclerosis. Lancet. 2008;372(9648):1502-17. https://doi.org/10.1016/S0140 -6736(08)61620-7.

129. Kirk J, Plumb J, Mirakhur M, McQuaid S. Tight junctional abnormality in multiple sclerosis white matter affects all calibres of vessel and is associated with blood-brain barrier leakage and active demyelination. J Pathol. 2003;201(2):319-27. https://doi. org/10.1002/path.1434.

130. Plumb J, McQuaid S, Mirakhur M, Kirk J. Abnormal endothelial tight junctions in active lesions and normal-appearing white matter in multiple sclerosis. Brain Pathol. 2002;12(2):154-69. https ://doi.org/10.1111/j.1750-3639.2002.tb00430.x.

131. Claudio L, Raine CS, Brosnan CF. Evidence of persistent bloodbrain barrier abnormalities in chronic-progressive multiple sclerosis. Acta Neuropathol. 1995;90(3):228-38. https://doi. org/10.1007/BF00296505.

132. Kazmierski R, Michalak S, Wencel-Warot A, Nowinski WL. Serum tight-junction proteins predict hemorrhagic transformation in ischemic stroke patients. Neurology. 2012;79(16):167785. https://doi.org/10.1212/WNL.0b013e31826e9a83.

133. Jiao X, He P, Li Y, Fan Z, Si M, Xie Q, et al. The role of circulating tight junction proteins in evaluating blood brain barrier disruption following intracranial hemorrhage. Dis Mark. 2015;2015:860120. https://doi.org/10.1155/2015/860120.

134. Annunziata P, Cioni C, Masi G, Tassi M, Marotta G, Severi S. Fingolimod reduces circulating tight-junction protein levels and in vitro peripheral blood mononuclear cells migration in multiple sclerosis patients. Sci Rep. 2018;8(1):15371. https://doi. org/10.1038/s41598-018-33672-9.

135. Fox E, Edwards K, Burch G, Wynn DR, LaGanke C, Crayton $\mathrm{H}$, et al. Outcomes of switching directly to oral fingolimod from injectable therapies: results of the randomized, open-label, multicenter, Evaluate Patient OutComes (EPOC) study in relapsing multiple sclerosis. Mult Scler Relat Disord. 2014;3(5):607-19. https://doi.org/10.1016/j.msard.2014.06.005.

136. Fox EJ, Lublin FD, Wolinsky JS, Cohen JA, Williams IM, Meng $\mathrm{X}$, et al. Lymphocyte counts and infection rates: long-term fingolimod treatment in primary progressive MS. Neurol Neuroimmunol Neuroinflamm. 2019;6(6):e614. https://doi.org/10.1212/ nxi.0000000000000614.

137. Kappos L, Li DK, Stuve O, Hartung HP, Freedman MS, Hemmer $\mathrm{B}$, et al. Safety and efficacy of siponimod (BAF312) in patients with relapsing-remitting multiple sclerosis: dose-blinded, randomized extension of the phase 2 BOLD study. JAMA
Neurol. 2016;73(9):1089-98. https://doi.org/10.1001/jamaneurol .2016.1451.

138. Cohen JA, Arnold DL, Comi G, Bar-Or A, Gujrathi S, Hartung JP, et al. Safety and efficacy of the selective sphingosine 1-phosphate receptor modulator ozanimod in relapsing multiple sclerosis (RADIANCE): a randomised, placebo-controlled, phase 2 trial. Lancet Neurol. 2016;15(4):373-81. https://doi.org/10.1016/ S1474-4422(16)00018-1.

139. Cohen JA, Comi G, Selmaj K, et al. Ozanimod vs interferon $\beta-1 \mathrm{a}$ : clinical and MRI results of RADIANCE part B-a 2-year Phase 3 trial in relapsing multiple sclerosis. Mult Scler. 2017;23(S3):981-2 (LB280). https://doi.org/10.1177/13524 58517733228.

140. Comi G, Kappos L, Selmaj K, et al. Ozanimod demonstrates efficacy and safety in a Phase 3 trial of relapsing multiple sclerosis (SUNBEAM). Mult Scler. 2017;23(S3):73-4 (Abstract 232). https://doi.org/10.1177/1352458517731283.

141. Koscielny V, Phase III. SUNBEAM and RADIANCE PART B trials for Ozanimod in relapsing multiple sclerosis demonstrate superiority versus interferon-beta-1a $(\operatorname{Avonex}((\mathrm{R})))$ in reducing annualized relapse rates and MRI brain lesions. Neurodegener Dis Manag. 2018;8(3):141-2. https://doi.org/10.2217/ nmt-2018-0012.

142. Bar-Or A, Zipp F, Scaramozza M, Vollmer T, Due B, Thangavelu K, et al. Effect of ceralifimod (ONO-4641), a sphingosine1-phosphate receptor-1 and -5 agonist, on magnetic resonance imaging outcomes in patients with multiple sclerosis: interim results from the extension of the DreaMS study (P3.161). Neurology. 2014;82(10 Supplement):P3.161;1526-632X.

143. Kappos L, Arnold DL, Bar-Or A, Camm J, Derfuss T, Kieseier $\mathrm{BC}$, et al. Safety and efficacy of amiselimod in relapsing multiple sclerosis (MOMENTUM): a randomised, double-blind, placebocontrolled phase 2 trial. Lancet Neurol. 2016;15(11):1148-59. https://doi.org/10.1016/S1474-4422(16)30192-2.

144. Kappos L, Arnold DL, Bar-Or A, Camm AJ, Derfuss T, Sprenger $\mathrm{T}$, et al. Two-year results from a phase 2 extension study of oral amiselimod in relapsing multiple sclerosis. Mult Scler. 2018;24(12):1605-16. https://doi.org/10.1177/1352458517728343.

145. Cree BAC, Arnold DL, Cascione M, Fox EJ, Williams IM, Meng $\mathrm{X}$, et al. Phase IV study of retention on fingolimod versus injectable multiple sclerosis therapies: a randomized clinical trial. Ther Adv Neurol Disord. 2018;11:1756286418774338. https:// doi.org/10.1177/1756286418774338.

146. Arnold DL, Cohen JA, Comi G, Selmaj KW, Bar-Or A, Steinman $\mathrm{L}$, et al. Ozanimod demonstrates preservation of brain volume at 1 and 2 years in two Phase 3 trials of relapsing multiple sclerosis (SUNBEAM and RADIANCE). Mult Scler. 2017;23(S3):986 (P1857).

147. Arnold DL, Fox RJ, Bar-Or A, Cree BAC, Giovannoni G, Gold $\mathrm{R}$, et al. Effect of siponimod on cortical grey matter and thalamic volume in patients with secondary progressive multiple sclerosis—results of the EXPAND study. Mult Scler. 2019;25(2 suppl):151-2 (P382).

148. Lublin F, Miller DH, Freedman MS, Cree BAC, Wolinsky JS, Weiner $\mathrm{H}$, et al. Oral fingolimod in primary progressive multiple sclerosis (INFORMS): a phase 3, randomised, double-blind, placebo-controlled trial. Lancet. 2016;387(10023):1075-84. https://doi.org/10.1016/S0140-6736(15)01314-8.

149. De Stefano N, Silva DG, Barnett MH. Effect of fingolimod on brain volume loss in patients with multiple sclerosis. CNS Drugs. 2017;31(4):289-305. https://doi.org/10.1007/s4026 3-017-0415-2.

150. Kihara Y, Zhu Y, Jonnalagadda D, Liu C, DSiddoway B, Dutta $\mathrm{R}$, et al. Differential CNS effects of siponimod vs fingolimod revealed by single-cell nuclear transcriptome analyses of human primary astrocytes. Mult Scler. 2019;25(S2):533 (P1008). 
151. Cree BAC, Fox RJ, Giovanonni G, Vermerch P, Bar-Or A, Gold $\mathrm{R}$, et al. Uncoupling the impact on relapses and disability progression: siponimod in relapsing and non-relapsing patients with secondary progressive multiple sclerosis in the phase III EXPAND study. Neurology. 2018;90(15 Supplement):S8.005.

152. Vermersch P, Gold R, Kappos L, Fox RJ, Bar-Or A, Cree BAC, et al. Siponimod delays the time to wheelchair in patients with SPMS: results from the EXPAND study. Mult Scler. 2019;25(S2):55 (Abstract 158).

153. Kuhle J, Kropshofer H, Barro C, Meinert R, Häring DA, Leppert D, et al. Siponimod reduces neurofilament light chain blood levels in secondary progressive multiple sclerosis patients. Neurology. 2018;90(15 Suppl):S8.006.
154. Brown B, Weiss JL, Kolodny S, Meng X, Williams IM, Osborne JA. Analysis of cardiac monitoring and safety data in patients initiating fingolimod treatment in the home or in clinic. BMC Neurol. 2019;19(1):287. https://doi.org/10.1186/s12883-019-1506-0.

155. Kappos L, O'Connor P, Radue EW, Polman C, Hohlfeld R, Selmaj K, et al. Long-term effects of fingolimod in multiple sclerosis: the randomized FREEDOMS extension trial. Neurology. 2015;84(15):1582-91. https://doi.org/10.1212/WNL.00000 00000001462 . 